\title{
Ueber die Elektrolytpermeabilität der roten Blutkörperchen.
}

\author{
Von H. Rohonyi (Budapest).
}

(Aus dem physiol. Institut der Königl. ung. Univ. Budapest. Direktor: Franz Tangl.)

(Fingegangen am 28, August 1916.)

1. Einleitung.

In halt.

11. Ueber die Aufnahme von Nitrit und Chlorat in rote Blutkörperchen.

a) Nachweis der Aufnahme von Nitrit.

b) Wird Nitritsalz oder das Nitrit-Ion aufgenommen?

c) Umtausch von Nitrit-Ion und Chlor-Ion.

d) Gasanalytische Untersuchungen.

e) Einwirkung von Kaliumchlorat.

f) Beeinflussungen der Nitrit- und Chloratwirkung.

g) Einwirkung von Nitrit in Gegenwart von Salzen auf rote Blutkörperchen.

h) Einwirkung von Nitrit in Gegenwart von Salzen auf hämolysiertes Blut und auf die Lösung von kristallisiertem Hämoglobin.

1II. Ueber die Aufnahme des Ferrizyankaliums.

a) Ferrizyan-Säure-Wirkung und Agglutination.

IV. Diskussion und Zusammenfassung.

I.

Wird von einem Stoffe erklärt, daß für denselben eine Zelle permeabel ist, so heibt dies soviel, dab die Zelle denselben aus seiner Lösung aufzunehmen vermag, so daß, falls die Zelle wieder entfernt wird, die Konzentration der ursprünglichen Lösung abgenommen hat, das fehlende Quantum aber in der Zelle vorzufinden ist. Bei der hier gegebenen Definition der Permeabilität sind zwei wesentliche Momente zu beachten: erstens, daß über den physikochemischen Mechanismus der Aufnahme des Stoffes nichts Näheres ausgesagt wird (ob der auf- 
genommene Stoff durch Diffusion, durch Auflösung oder aber durch Adsorption in die Zelle gelangt), zweitens, daß bei dieser Definition auf den Unterschied zwischen Eindringen in das Innere der Blutzelle und Fixierung auf der Oberfläche der Blutzelle kein Gewicht gelegt wird, sondern bloß jene Frage Beachtung findet, ob der betreffende Stoff nach Entfernung der Zelle sich ebenfalls aus der Lösung entfernt oder nicht. In Anbetracht des gegenwärtigen Standes der Lehre über die Permeabilität erscheint diese Definition zweckmäßig, denn so kann jede hierher gehörende Erscheinung, unbeachtet der gegenwärtigen Unsicherheit der Zellen-Struktur, sowie des physikochemischen Mechanismus der Aufnahme, hier dennoch besprochen werden. Die präzisere Fassung des Begriffes der Permeabilität nach "der einen oder anderen Richtung hin wird erst dann möglich werden, wenn die diesbezüglichen Forschungen die endgültige Lösung der erwähnten Probleme zeitigen werden.

Bis die Besprechung und Klassifizierung dieser Erscheinungen. auf der einzigen exakten Basis, d. h. nach jenen physikochemischen Vorgängen, die sich in denselben offenbaren, möglich sein wird, erscheint es zweckmäßig, die Permeabilität nach der Natur des aufgenommenen Stoffes zu unterscheiden: 1. Permeabilität der Kolloide, 2. der organischen Kristalloide und 3. der anorganischen Kristalloide (d. h. der Elektrolyte). Daß diese Unterscheidung nicht ganz ephemerer Art ist, erscheint durch den Umstand bestätigt, daß bekanntlich die Aufnahme der in diese drei Gruppen klassifizierten chemischen Stoffe in die Zelle durch ganz verschiedenartige Gesetzmäßigkeiten bedingt ist, so zwar, daß der Umstand, ob ein Stoff zu den Kolloiden oder organischen Kristalloiden oder den Elektrolyten zählt, auch hinsichtlich der Aufnahme desselben in die Zelle ausschlaggebend ist.

Die Aufnahme der Kolloid-Körper (unter denselben ein großer Teil der Farbstoffe) in die Zelle wurde in zahllosen Fällen untersucht; auf Grund dieser Untersuchungen wurden hinsichtlich des Mechanismus der Aufnahme verschiedene Konklusionen gezogen. Es steht außer Zweifel, daß heute die Aufnahme der Kolloide auf der einfachsten und allgemeinsten Weise durch die $\mathrm{Ruhland}$ ('sche Theorie beschrieben werden kann ${ }^{1}$ ); hinsichtlich der Permeabilität der Kolloide sind jene ihrer Eigenschaften maßgebend, welche zugleich die Geschwindigkeit ihrer Diffusion in irgend ein Gel bestimmen, also in erster Reihe der Grad ihrer Dispersität. Je rascher irgend ein Kolloid.

1) Ber. d. Deutsch. botan. Ges. 30, 139 (1912). 
in ein Gelatine- oder anderes Gel diffundiert, desto rascher wird dasselbe von der Zelle aufgenommen. Die elektrische Ladung oder die chemische Natur usw. des Kolloidteilchens kommt bloß nebensächlich und insofern in Betracht, als all dies bloß dafür maßgebend ist, ob in der Zelle das aufgenommene Kolloid gebunden wird oder nicht; die Geschwindigkeit der Aufnahme jedoch wird durch diese Eigenschaften nicht beeinträchtigt.

Die Gesetzmäßigkeit der Permeabilität der organischen Kristallo ide wird durch die Lipoid-Theorie, welche bis zur neuesten Zeit allgemeine Geltung besaß, bekanntlich folgendermaßen beschrieben: Die Blutzelle nimmt umsomehr von dem betreffenden Stoffe auf, je besser sich derselbe in Lipoiden oder in Lösungsmitteln der Lipoide auflösen läßt. Die Erklärung dieses Zusammenhanges zwischen Permeabilität und Lipoidlöslichkeit wäre durch den Umstand gegeben, daß die Zellen-Membran ausschließlich oder zumindest überwiegend aus Lipoiden besteht. Diese Theorie hat bei ihren unbestreitbaren Erfolgen mit vielen Schwierigkeiten zu kämpfen; heute scheint die Traube'sche Theorie, durch welche die auch in der Lipoid - Theorie mehr oder weniger erklärten Tatsachen ohne etwaige spezielle Hypothesen über die Natur der Zellen-Membran ausgelegt werden, zur Beschreibung der gesamten hierher gehörigen Erscheinungen besser geeignet zu sein ${ }^{1}$ ). Nach T raube werden die Stoffe in jener Reihenfolge aufgenommen, in welcher dieselben die Oberflächenspannung der Zellen-Membran vermindern.

Während über die Permeabilität der Kolloide und organischen Kristalloide in den erwähnten Theorien sehr weitgehende Kenntnisse niedergelegt erscheinen, sind hinsichtlich der Aufnahme der Elektroly te selbst die elementaren Grundbedingungen nicht geklärt Die Lehre über den osmotischen Druck der Zellen stützte sich darauf, daß die im Inneren der Zelle befindliche Elektrolytlösung von einer für Salzlösungen semipermeablen Membran umgeben ist. Die von $\mathrm{Ham}$ burger, Gryns, Hedin und anderen mittelst verschiedener Methodik vorgenommenen Untersuchungen ergaben, daß die anorganischen Salze nicht in die Zelle aufgenommen werden; ja, nach Bethe und Warburg ist dies (mit Ausnahme des Ammoniaks), auch hinsichtlich Laugen und Säuren nicht der Fall ${ }^{2}$ ).

Andererseits wurde nachgewiesen, daß, wenngleich die Salzmoleküle auch nicht in die Zelle aufgenommen werden, gewisse Bestandteile

1) Pflüger's Arch. 123, 419 (1908).

2) Bethe, Pflüger's Arch. 127, 219 (1909); Warburg, Biochem. Zeitschr. 29, $414(1910)$. 
derselben ohne Zweifel in die Zelle gelangen können. So hat zum Beispiel Bönniger nachgewiesen, daß die roten Blutkörperchen Brom aus der Lösung der Alkalibromide aufnehmen ${ }^{1}$ ); auch ist es eine längst bekannte Tatsache, daß die Zellen des mit Kohlensäure durchströmten Blutes vom Serum Chlor entziehen usw. Zur Auslegung dieser Tatsachen hat Ko e p p e seine Theorie ${ }^{2}$ ) über die Ionenpermeabilität der Zellen aufgestellt, nach welcher die Salzmoleküle nicht, wohl aber einzelne Ionen durchdringen können; die gegenseitige Wanderung der Anionen durch die Blutkörperchen-Oberfläche hindurch wird durch Diffusionskräfte bewirkt. Mit der freien Diffusion der Anione stimmen viele Feststellungen überein, ein wichtiger Umstand ist aber mit dieser Deutung bisher unvereinbar, nämlich die Differenzen im Gehalt an den einzelnen Anionen, welche $z$ wischen Blutkörperchen und Serum offenbar bestehen $\left(\mathrm{Höber}^{3}\right)$. Wird aber die Ionenpermeabilität nicht auf die verschiedenen Diffusionen der Ionen basiert, so kann sie die Folge einer Adsorption oder chemischen Bindung der lonen sein. In diesem Sinne hat die Permeabilität der Zelle für irgend ein Ion soviel zu bedeuten, daß jenes Ion in der Zellenmembran oder in dem Zellenprotoplasma (durch Adsorption oder chemische Reaktion) gebunden wird; impermeabel aber ist die Zelle für jenes lon, welches auf solche Weise nicht gebunden wird.

Meine Experimente haben sich auf Untersuchung dieser Hypothese und auf die eingehende Klärung derselben gerichtet. Der Grundgedanke meiner Untersuchungen war folgender: Zur Untersuchung der Elektrolytpermeabilität sind Zellen zu gebrauchen, welche einen Stoff enthalten, der in Gegenwart des Elektrolyts leicht eine Veränderung aufweist; andererseits sind solche Elektrolyte zu prüfen, welche zur Hervorbringung dieser Veränderung besonders geeignet sind. Sodann ist die Einwirkung des Elektrolyts auf den betreffenden Körper einmal, wenn sich derselbe in reiner wässeriger Lösung befindet, zu prüfen, und daraufhin ist hiermit die Einwirkung des Elektrolyts dann zu vergleichen, wenn es auf den in der Zelle befindlichen Körper einwirkt; solcherart wird sich die Rolle der Zellenstruktur, sowie jene der Zellenmembran offenkundig zeigen.

Diesen Vorbedingungen ist leicht Genüge zu tun, wenn die Veränderung des Hämoglobins der roten Blutkörperchen bei Einwirkung der Elektrolyte untersucht wird. Vom Hämoglobin

1) Bönniger, Zeitschr. f. exp. Path. u. Therap. 4, 417 (1904).

2) Koeppe, Pflüger's Arch. 67, 189 (1897).

3) Höber, Physik. Chem. d. Zelle (Leipzig 1911), 500. 
ist es bekannt, daß zahlreiche Stoffe die Umwandlung desselben in Methämoglobin bewirken, was sich in leicht wahrnehmbaren Veränderungen kundgibt; unter diesen Stoffen sind die Nitrite, Chlorate, Ferrizyanide usw. Elektrolyte. Diese Reaktion des Hämoglobins kann in roten Blutkörperchen, und nach Hämolyse, ohne Mitwirkung der Zellenstruktur, in wässeriger Lösung beobachtet werden. Das Verhalten der verschiedensten Stoffe auf diese Reaktion kann in der Blutzelle und in der Lösung verglichen werden, wodurch hinsichtlich der Permeabilität dieser Stoffe indirekte Konklusionen gezogen werden können.

Meine Untersuchungen beziehen sich vor allem auf die Frage der Permeabilität der roten Blutkörperchen und gewinnen dadurch allgemeine Gültigkeit, da nach den bisherigen Kenntnissen die Verhältnisse der Permeabilität der roten Blutkörperchen und anderer animaler sowie pflanzlicher Zellen keine wesentlichen Unterschiede aufweisen.

II.

Ueber die Aufnahme von Nitrit und Chlorat in rote Blutkörperchen.

Wird zu Blut oder zu hämolysiertem Blut oder zu einer Hämoglobinlösung etwas (Zehntelnormal) Kalium- oder Natriumnitritlösung getropft, so werden wir nach ein bis zwei Sekunden wahrnehmen, daß das vorher noch lebhaft rote Blut oder Lösung sich dunkel bräunlichrot färbt. Diese Aenderung des Hämoglobins wurde von Gamgee und nach ihm von vielen anderen eingehend studiert; es wurde festgestellt, daß im Verlaufe der Reaktion das Hämoglobin sich in Methämoglobin umwandelt, dessen Spektrum sich von jenem des Methämoglobins, welches infolge Einwirkung der Ferrizyansalze erzeugt wurde, einigermaßen unterscheidet; daß ein Mol Kaliumnitrit mit einem Mol Hämoglobin reagiert; daß das Reaktionsprodukt eine AdditionsVerbindung zwischen dem Nitritsalz und Hämoglobin ist usw. Bei den durch Nitritsalze verursachten Vergiftungsfällen hat sich herausgestellt, daB die Blutzellen in solchen Fällen teilweise Nitritmethämoglobin enthalten. Die physikochemischen Vorbedingungen des Verlaufes der Reaktion wurden jedoch, soweit ich weiß, bisher nicht untersucht, weder die in der Blutzelle, noch die in der Lösung vorgehende Reaktion betreffend. 
a) Nachweis der Aufnahme von Nitrit.

Vor allem prüfte ich, wieviel Nitritsalz von der äuBeren Lösung während der Zeit, in der die Nitritreaktion in der roten Blutzelle vorgeht, verschwindet.

Ich zentrifugierte frisches, defibriniertes Rinderblut und wusch die Zellen 4-5 mal mit 0,85 prozentiger Kochsalzlösung. $\mathrm{Zu}$ der so gewonnenen kochsalzhaltigen Blutzellen-Suspension gab ich abgemessene Mengen von Normal-Natriumnitritlösung. Nach erfolgtem Durchschütteln bräunten sich sofort die Zellen; nach 10-15 Minuten stellte ich mittelst des Hämokrites in der Suspension das Blutzellen-Volum fest sowie in der äußeren Lösung durch Titrierung mit Kalium - Permanganat die Konzentration des Natriumnitrites. (Nachdem die Zellen vorher gründlich ausgewaschen wurden, blieb vom ursprünglichen Serum keinerlei reduzierender Körper zurück, wovon ich mich in jedem einzelnen Falle eigens überzeugte in der Weise, daß ich die letzte Waschflüssigkeit mit einigen Tropfen n/10 Permanganatlösung versetzte; in keinem Falle trat eine Reduktion der Permanganatlösung ein.)

Als Beispiel möge ein Versuch ausführlich beschrieben werden:

Die Zellen von defibriniertem Rinderblut werden mehrmals mit Kochsalzlösung ausgewaschen. $\mathrm{Zu} 50 \mathrm{ccm}$ dieser Suspension werden $5 \mathrm{ccm} \mathrm{n} 1 \mathrm{NaNO}_{2}$-Lösung hinzugefügt; in diesen $5 \mathrm{ccm}$ sind nach vorhergehender Bestimmung 0,270 $\mathrm{g} \mathrm{NaNO}_{2}$ enthalten. Blutzellenvolum, gemessen mittelst des Hämotokriten: 47 Proz., d. h. die $55 \mathrm{ccm}$-Suspension enthält $26 \mathrm{ccm}$ Zelle (A) und $29 \mathrm{ccm}$ Lösung (B). Die Titrierung von B ergibt einen Gehalt von $0,0063 \mathrm{~g}$ pro $\mathrm{ccm}$, mithin in $29 \mathrm{ccm}$ $0,182 \mathrm{~g}$. Also sind von den zugesetzten $0,270 \mathrm{~g} 0,088 \mathrm{~g} \quad(=0,270$ - 0,182) verschwunden. Soviel fällt auf $26 \mathrm{ccm}$. Zelle; auf $1 \mathrm{ccm}$ Zelle fallen $0,0034 \mathrm{~g}$, was (wenn das ganze Volum der Zelle als eine wässerige Lösung betrachtet wird) einer $n / 20$-Lösung entspricht.

Die aus drei solchen Versuchen erhaltenen Daten lasse ich in der nachfolgenden Tabelle folgen:

Tabelle I.

\begin{tabular}{|c|c|c|c|c|c|}
\hline $\begin{array}{l}\text { Nr.d. } \\
\text { Versuchs }\end{array}$ & $\begin{array}{l}\text { Zur Blutsus- } \\
\text { pension: hin- } \\
\text { Zugegebene } \\
\text { Nitritmenge } \\
\text { in } \mathrm{g}\end{array}$ & $\begin{array}{c}\text { g } \mathrm{Na} \mathrm{NO}_{2} \\
\text { in der } \\
\text { in der } \\
\text { Lösung }\end{array}$ & $\begin{array}{c}\mathrm{g} \mathrm{NaNO}_{2} \\
\text { verschwun- } \\
\text { den aus der } \\
\text { Lösung }\end{array}$ & $\begin{array}{l}\text { Blut- } \\
\text { korperchen- } \\
\text { volum }\end{array}$ & $\begin{array}{c}\text { Konzen- } \\
\text { tration der } \\
\text { Blutkörper- } \\
\text { chen an } \\
\mathrm{NaNO}_{2}\end{array}$ \\
\hline 1 & 0,162 & 0,120 & 0,042 & 33 Proz. & $\mathrm{n} / 16$ \\
\hline 2 & 0,270 & 0,182 & 0,088 & $47 \quad$ & $\mathrm{n} / 20$ \\
\hline 3 & 0,270 & 0,216 & 0,054 & 28 & $\mathrm{n} / 16$ \\
\hline
\end{tabular}


Aus dieser Tabelle geht hervor, daß die in Kochsalzlösung suspendierten roten Blutkörperchen eine beträchtliche Nitritmenge aufzunehmen vermögen.

b) Wird Nitritsalz oder das Nitrit-Ion aufgenommen?

Die zweite Frage war, in welcher Form das zu den Blutkörperchen gegebene Nitritsalz aufgenommen wird: gelangen undissoziierte Nitritmoleküle oder die Ionen in die Zelle? und welches Verhältnis besteht im letzten Falle zwischen der Aufnahme des Kations und des Anions?

Zur Untersuchung dieser Frage verwendete ich anstatt $\mathrm{NaNO}_{2}$ das Kalziumsalz, $\mathrm{Ca}\left(\mathrm{NO}_{2}\right)_{2}$, da dies ein Nitritsalz ist, bei welchem sich auch das Kation mit Leichtigkeit bestimmen läBt. Die Suspension der mit Rohrzuckerlösung ausgewaschenen roten Blutkörperchen versetzte ich mit einer genau abgemessenen Menge einer $\mathrm{Ca}\left(\mathrm{NO}_{2}\right)_{2}$ Lösung und zentrifugierte sie nach kräftigem Durchschütteln. Dann titrierte ich in einer Portion der über den roten Blutkörperchen stehenden klaren Flüssigkeit den Nitritgehalt; in einer anderen Portion fälte ich das Kalzium mittelst Ammoniumoxalates und titrierte den entsprechend behandelten Oxalatniederschlag mit Permanganat und erhielt auf diese Weise den Kalziumgehalt.

Als Beispiel diene Versuch 3 der Tab. II. Rote Blutkörperchen von Rinderblut werden mit 8 Proz. Rohrzuckerlösung bis zum Verschwinden der Chlorreaktion in der Waschflüssigkeit an der Zentrifuge gewaschen. Zugleich wird konstatiert, daß $5 \mathrm{ccm}$ der Waschflüssigkeit eine $\mathrm{m} / 100 \mathrm{KMnO}_{4}$-Lösung bei $40^{\circ} \mathrm{C}$ nicht reduzieren. $35 \mathrm{ccm}$ der Zellensuspension werden nun mit $5 \mathrm{ccm}$ einer $\mathrm{m} / 8 \mathrm{Ca}\left(\mathrm{NO}_{2}\right)_{2}$-Lösung versetzt; $1 \mathrm{ccm}$ der $\mathrm{Ca}\left(\mathrm{NO}_{2}\right)_{2}$-Lösung enthält $4,478 \mathrm{mg} \mathrm{Ca}$ und $10,20 \mathrm{mg} \mathrm{NO}_{2}$. Nach Schütteln ist die Suspension braunrot gefärbt. Volum der Blułkörperchen in der mit $\mathrm{Ca}\left(\mathrm{NO}_{2}\right)_{2}$-Lösung versetzten Suspension mit Hämotokrit bestimmt $=43$ Proz. Die Zellensuspension wird jetzt zentrifugiert; in einem Teile der obenstehenden Lösung wird Nitrit-Bestimmung, im anderen Teile Kalzium-Bestimmung vorgenommen. Ich fand in $1 \mathrm{ccm}$ der Lösung $0,982 \mathrm{mg} \mathrm{Ca}$ und $1,189 \mathrm{mg} \mathrm{NO}_{2}$. Um zu erfahren, wieviel $\mathrm{Ca}$, bzw. wieviel $\mathrm{NO}_{2}$, aus der Lösung verschwunden ist, berechne ich, wieviel davon vorzufinden wäre, wenn vom $\mathrm{Ca}\left(\mathrm{NO}_{2}\right)_{2}$ gar nichts verschwunden wäre. Nachdem das Blutzellen-Volum 43 Proz. macht, bestand die $40 \mathrm{ccm}$-Suspension aus $22,8 \mathrm{ccm}$ Lösung und 17,2 $\mathrm{cm}$ Blutkörperchen; die $5 \mathrm{ccm} \mathrm{Ca}\left(\mathrm{NO}_{2}\right)_{2}$ Lösung wurde also auf $22,8 \mathrm{ccm}$ verdünnt, d. h. ihre Konzentration hat sich 0,219 fach vermindert. Demgemäß müßte die Lösung (wenn 
weder $\mathrm{Ca}$, noch $\mathrm{NO}_{2}$ aus ihr verschwunden wäre) in $1 \mathrm{ccm} 4,478$. $0,219=0,980 \mathrm{mg} \mathrm{Ca}$, und $10,2 \cdot 0,219=2,234 \mathrm{mg} \mathrm{NO} \mathrm{N}_{2}$ enthalten. Ein Vergleich mit den gefundenen Werten zeigt sofort, daß $\mathrm{Ca}$ nicht, vielmehr $\mathrm{NO}_{2}$ in sehr bedeutender Menge aus der Lösung verschwunden ist.

Die nachfolgende Tabelle enthält die aus fünf Versuchen erhaltenen Ergebnisse; überall wurde berechnet, wieviel Kalzium, bzw. Nitrit-Ion, in der Lösung vorzufinden sein müßte, wenn die Zelle davon nichts. in sich aufgenommen hätte. In der vorletzten Rubrik der Tabelle ist angeführt, wieviel Proz. des hinzugegebenen $\mathrm{NO}_{2}$ abgegangen ist; die letzte Rubrik zeigt die auf $1 \mathrm{ccm}$ Blutkörperchen entfallenden Nitritquantitäten in $\mathrm{mg}$.

Tabelle II.

\begin{tabular}{|c|c|c|c|c|c|c|c|}
\hline $\begin{array}{l}\text { Nr. d. } \\
\text { Ver- } \\
\text { suchs }\end{array}$ & $\begin{array}{l}\text { Blut- } \\
\text { körper- } \\
\text { chen- } \\
\text { volum }\end{array}$ & $\begin{array}{l}\text { Ca } \\
\text { berechnet } \\
\mathrm{mg} \\
\text { in } 1 \mathrm{ccm}\end{array}$ & $\begin{array}{c}\mathrm{Ca} \\
\text { gefunden } \\
\mathrm{mg} \\
\text { in } 1 \mathrm{ccm}\end{array}$ & $\begin{array}{c}\mathrm{NO}_{2} \\
\text { berechnet } \\
\text { mg } \\
\text { in } 1 \mathrm{ccm}\end{array}$ & $\begin{array}{l}\mathrm{NO}_{2} \\
\text { gefunden } \\
\text { mg } \\
\text { in } 1 \mathrm{ccm}\end{array}$ & $\begin{array}{c}\text { Ver- } \\
\text { schwund. } \\
\mathrm{NO}_{2} \\
\text { Proz. }\end{array}$ & $\begin{array}{c}\mathrm{NO}_{2} \\
\text { pro ccm } \\
\text { Blut- } \\
\text { körperch. }\end{array}$ \\
\hline 1 & 34,5 & 3,40 & 3,49 & 7,85 & 6,74 & 15,4 & 2,11 \\
\hline 2 & 30,0 & 3,65 & 3,57 & 8,53 & 7,60 & 10,9 & 2,17 \\
\hline 3 & 43,0 & 0,98 & 0,98 & 2,23 & 1,19 & 47,1 & 1,40 \\
\hline 4 & 35,5 & 0,98 & 0,94 & 2,28 & 1,52 & 33,3 & 1,38 \\
\hline 5 & 46,0 & 1,18 & 1,16 & 2,72 & 1,47 & 46,0 & 1,45 \\
\hline
\end{tabular}

Aus dieser Tabelle geht unzweifelhaft hervor, dab die roten Blutkörperchen zur Zeit, wo sie den Nitrit-Bestandteil in grober Menge aufnehmen, aus einer $\mathrm{Ca}\left(\mathrm{NO}_{2}\right)_{2}$ - $\mathrm{Lösung}$ nicht zugleich Kalzium aufnehmen. Im gegenwärtigen Falle erscheint es also unzweifelhaft nachgewiesen, was durch indirekte Beweise bekräftigt längst behauptet wurde, dab die Zelle "ionenpermeabel" ist.

Die letzte Rubrik der Tabelle zeigt, daß das durch die Volumeinheit der roten Blutkörperchen aufgenommene Nitritquantum von der Konzentration des hinzugegebenen $\mathrm{Ca}\left(\mathrm{NO}_{2}\right)_{2}$ abhängt; bei den ersten zwei Experimenten fällt dieselbe, weil das Quantum des hinzugegebenen Ca $\left(\mathrm{NO}_{2}\right)_{2}=5$ größer war, bedeutend größer aus $(2,11$ und 2,17$)$, als beim dritten, vierten und fünften Experiment $(1,40,1,38,1,45)$, wo weniger $\mathrm{Ca}\left(\mathrm{NO}_{2}\right)_{2}$ hinzugegeben wurde. Wurde aber bei zwei Experimenten (dritten und vierten) das gleiche Quantum $\mathrm{Ca}\left(\mathrm{NO}_{2}\right)_{2}$ zu den. Zellen gegeben, so fiel die auf die Volumeinheit der Zelle entfallende Menge Nitrit ebenfalls gleich aus $(1,40$ und 1,38). 
c) Umtausch von Nitrit-Ion und Chlor-Ion.

Es ist auf elementaren elektrochemischen Prinzipien begründet, dab das Anion eines Salzes nur dann ohne das entsprechende Kation von der Zelle auffgenommen wird, wenn an Stelle des aufzunehmenden Anions ein anderes Anion aus der Zelle scheidet. Diese Vorbedingung hat bereits Koeppe zur Chlor-Permeabilität der roten Blutkörperchen zufolge der Säure-Einwirkung gestellt. Bei einem anderen Falle hat sodann Bö n n i g e r hinsichtlich der natürlichen Brom-Ion-Permeabilität der roten Blutkörperchen die Stichhaltigkeit dieser Vorbedingung nachgewiesen; B ö n n ig e r fand, daß die roten Blutkörperchen bei Aufnahme der Brom-Ionen Chlor-Ionen abgeben.

Die roten Blutkörperchen enthalten außer den Chlor-Ionen auch andere, insbesondere Phosphat- und Karbonat-Ionen; vermutlich können an Stelle des aufgenommenen Anions außer den Chlor-Ionen auch diese hinzutreten. Da jedoch im Verhältnis zur Konzentration der Chlorlonen sonstige lonen in verschwindend kleiner Menge in roten Blutkörperchen vorhanden sind, habe auch ich bei meinen diesbezüglichen Untersuchungen mein Augenmerk ausschließlich auf den Umtausch der Nitrit-Chlor-Ionen gerichtet.

Kann der Chlor-Ionengehalt der roten Blutkörperchen durch NitritIonen ersetzt werden? Tritt an Stelle eines jeden aufgenommenen Nitrit-Ions Chlor-Ion heraus, so wird nach Waschen der roten Blutkörperchen mit isotonischer Nitritlösung deren Chlorgehalt stetig abnehmen, so weit, daß das Chlor endlich ganz aus den Zellen verschwinden wird; werden andererseits die durch Waschen mit einer Nitritlösung von ihrem Chlorgehalt befreiten Blutkörperchen wieder mit isotonischer Kochsalzlösung behandelt, werden sie wieder Chlor aufnehmen.

Ich wusch den einen Teil der Zellen von defibriniertem Rinderblut mit isotonischer Rohrzuckerlösung, einen zweiten Teil davon mit $m / 8$ $\mathrm{Ca}\left(\mathrm{NO}_{2}\right)_{2}$-Lösung mehrmals an der Zentrifuge; ein dritter Teil wurde nach dem Auswaschen mit der $\mathrm{m} / 8 \mathrm{Ca}\left(\mathrm{NO}_{2}\right)_{2}$-Lösung weiter mehrmals mit physiol. Kochsalzlösung und endlich mit isotonischer Rohrzuckerlösung (bis zum Verschwinden der $\mathrm{Cl}^{\prime}$ - Reaktion in der Waschflüssigkeit) gewaschen. In je $5 \mathrm{ccm}$ des nach dem letzten Waschen eine halbe Stunde lang zentrifugierten Blutkörperchenbreies bestimmte ich den Chlorgehalt. Die Chloranalyse erfolgte nach Volhard, nachdem vorher der Blutkörperchenbrei in Gegenwart von Salpetersäure mit Kaliumpermanganat zerstört und das überflüssige Permanganat mit Ferrosulfat reduziert wurde (Methode von v. Korányi). 
Die nachfolgende Tabelle enthält die Ergebnisse dreier solcher Versuche. Die Zahlen geben an, wieviel $\mathrm{mg}$ Chlor in $5 \mathrm{ccm}$ Blutkörperchen gefunden wurden.

Tabelle III.

\begin{tabular}{c|c|c|c}
\hline $\begin{array}{c}\text { Nr. des } \\
\text { Versuchs }\end{array}$ & $\begin{array}{c}\text { Nach Waschen } \\
\text { mit isotonischer } \\
\text { Rohrzuckerlösung }\end{array}$ & $\begin{array}{c}\text { Nach Waschen } \\
\text { mit m/8 } \\
\text { Ca (NO2 })_{2} \text {-Lösung }\end{array}$ & $\begin{array}{c}\text { Nach Waschen } \\
\text { 1.mit m/8 Ca }\left(\mathrm{NO}_{2}\right)_{2}-\text { Lös. } \\
\text { 2. physiol. Kochsalzoung } \\
\text { 3. isoton. Rohrzuckerlösung }\end{array}$ \\
\hline 1 & 5,6 & 0,12 & 6,2 \\
2 & 7,1 & 0,05 & 9,3 \\
3 & 6,5 & 0,12 & 6,3
\end{tabular}

Diese Zahlen zeigen, 1. daß durch Waschen mit den NitritIonen das Chlor-Ion bis auf einen Gehaltvon 0,002 Proz. Chlor aus den roten Blutkörperchen entfernt werden kann, 2. dab die aufgenommenen Nitrit-Ionen durch Waschen mit physiol. Kochsalzlösung wieder durch ClIonen ersetzt werden können.

Aendert sich im Serum die Chlor-Konzentration, wenn zum Blut Nitritsalz gegeben wird?

Bei den vorherigen Experimenten wurden die roten Blutkörperchen mit (chlorfreier) $\mathrm{Ca}\left(\mathrm{NO}_{2}\right)_{2}$-Lösung gewaschen; die Blutkörperchen haben also ihren Chlorgehalt in ein Medium abgegeben, welches keine Chlor-Ionen besaß; bei meinen nachfolgenden Experimenten dagegen beobachtete ich den Umtausch der Chlor-Nitrit-Ionen in einem Medium - nämlich im Serum -, welches auch selbst Chlor-Ionen enthält. Das Rinderblut-Serum ist bekanntermaßen eine Lösung, in welcher die Konzentration der Chlor-lonen die der roten Blutkörperchen ungefähr um das Zweieinhalbfache übersteigt; die Frage war, ob während der Aufnahme der Nitrit-Ionen auch im Blute der Chlorgehalt der roten Blutkörperchen abnimmt, ob also gegen die Richtung des partiellen osmotischen Druckes ein Umtausch der Chlor-Ionen erfolgen kann?

Ich filtrierte defibriniertes Rinderblut mehrfach durch Gaze; das derart gereinigte Blut teilte ich in zwei Teile. Den einen Teil (1.) zentrifugierte ich und bestimmte den Chlorgehalt des Serums; zugleich bestimmte ich mittelst des Hämatokrites auch das Zellenvolumen des Blutes. Vom anderen Teile des Blutes (2.) maB ich $50 \mathrm{ccm}$, gab $5 \mathrm{ccm}$ n/1 $\mathrm{NaNO}_{2}$ hinzu, worauf ich das Blut zentrifugierte; sodann bestimmte ich den Chlorgehalt des derart gewonnenen Serums und das Zellenvolumen des $\mathrm{Na} \mathrm{NO}_{2}$ enthaltenden Blutes. An Hand dieser Daten kann mit Leichtigkeit berechnet werden, ob zufolge der Einwirkung 
des Nitritsalzes ein Chlorumtausch im Blute vorgegangen ist und wenn ja, in welchem Maße? Um dies beurteilen zu können, erschien es zweckmäßig, die Chloränderung auf $1 \mathrm{ccm}$ roter Blutzellen zu berechnen. Die hierauf berechnete Formel lautet wie folgt:

$$
\mathrm{V}=\frac{\mathrm{B}\left(\frac{100-\beta}{100}\right) \frac{\mathrm{Cl}_{\mathrm{B}}}{5}-\mathrm{A}\left(\frac{100-\alpha}{100}\right) \frac{\mathrm{Cl}_{\mathrm{A}}}{5}}{\mathrm{~A} \frac{\alpha}{100}},
$$

wo $A=$ Blutmenge im 2. Teile des Versuchs $(50 \mathrm{ccm})$

$B=A+$ Volum der $\mathrm{NaNO}_{2}$-Lösung im 2. Teile des Versuchs $(=55 \mathrm{ccm})$

$\alpha=$ Blutkörperchenvolum im 1. Teile des Versuchs

$\beta=\quad, 2$, " , "

$\mathrm{Cl}_{\mathrm{Ai}}=\mathrm{ccm} \mathrm{AgNO} \mathrm{O}_{3}$ verbraucht beim Titrieren von $5 \mathrm{~cm}$ Serum im 1. Teile des Versuchs

$\mathrm{Cl}_{\mathrm{B}_{4}}=\mathrm{ccm} \mathrm{AgNO} \mathrm{O}_{3}$ verbraucht beim Titrieren von $5 \mathrm{ccm}$ Serum im 2. Teile des Versuchs

$\mathrm{V}=$ Aenderung des Chlorgehalts von $1 \mathrm{ccm}$ Blutkörperchen in mg $\mathrm{Cl}^{\prime}$ ausgedrückt (wenn $\mathrm{V}$ positiv, ist eine Verminderung, wenn negativ, eine Vermehrung des Chlorgehalts vorhanden).

Ich unternahm zwei derartige Experimente, deren Ergebnisse in der nachstehenden Tabelle folgen:

Tabelle IV.

\begin{tabular}{c|c|c|c||c|c|c|c}
\hline \hline $\begin{array}{c}\text { Nr.des des } \\
\text { Versuchs }\end{array}$ & $\mathrm{A}$ & $\boldsymbol{\alpha}$ & $\mathrm{Cl}_{\mathrm{A}}$ & $\mathrm{B}$ & $\boldsymbol{\beta}$ & $\mathrm{Cl}_{\mathrm{B}}$ & $\mathrm{V}$ \\
\hline \hline 1 & 50 & 51 & 11,24 & 55 & 41 & 10,02 & 0,699 \\
2 & 50 & 41 & 11,90 & 60 & 32 & 9,40 & 0,568
\end{tabular}

In beiden Experimenten war also eine Verminderung des Chlorgehaltes der roten Blutkörperchen zu konstatieren; die Verminderung macht etwa 50 Proz. des normalen Chlorgehaltes des roten Blutkörperchens (s. Tabelle III, S. 346) aus. Wird also zu Blut is otonische Nitritlösung hinzugefügt, so tritt aus den roten Blutkörperchen Chlor entgegen seinem partiellen osmotischen Drucke in das Serum. Diese Tatsache beweist eklatant, daf dieser Ionenaustausch kein Diffusionsvorgang sein kann.

Es hat sich also bisher herausgestellt, daB die roten Blutkörperchen nicht das Nitritsalz, sondern das Nitrit-lon aufnehmen; das Nitrit-Ion 
tritt in die roten Blutkörperchen an Stelle der Chlor-Ionen; die solcherart freigewordenen Chlor-Ionen wandern in das Serum. Von den aufgenommenen Nitrit-lonen verbindet sich bloß ein kleiner Teil mit dem Hämoglobin, die übrigen behalten ihre Form und können durch ChlorIonen ersetzt werden.

Es unterliegt keinem Zweifel, daß die Nitrit-Hämoglobin-Reaktion nur dann vor sich gehen kann, wenn das Nitrit-lon aufgenommen wurde; wird die Aufnahme des Nitrit-Ions verhindert, so wird die Reaktion nicht erfolgen; wird sie befördert, wird sie in größerer Konzentration aufgenommen, so wird auch die Reaktion rascher von statten gehen. Umgekehrt kan von der Geschwindigkeit der Reaktion - sofern die Einwirkung sonstiger Faktoren ausgeschlossen werden kann - auf das Quantum der aufgenommenen Nitrit-Ionen Folgerung gezogen werden.

Die Geschwindigkeit der Nitritreaktion kann auf zweierlei Art beobachtet werden. Quantitativ wird die Reaktion verfolgt, indem die $\mathrm{Quantitäten} \mathrm{des} \mathrm{inzwischen} \mathrm{erzeugten} \mathrm{Methämoglobins} \mathrm{zeitweise}$ festgestellt werden. Um Vergleiche vorzunehmen, genügt es jedoch, den Farbenumschlag zu bestimmen, welcher mit der Bildung des Methämoglobins eintritt.

d) Gasanalytische Untersuchungen.

Wird zu defibriniertem Rinderblut etwas hypertonische Kaliumnitritlösung hinzugegeben, so wird sich nach einigen Sekunden das vorher noch lebhaft rote Blut dunkel bräunlichrot färben. Nach Zentrifugieren können wir konstatieren, daß keine Hämolyse erfolgt ist ; die Reaktion ging also in der Zelle von statten. Vom Hämoglobin unterscheidet sich das entstandene Methämoglobin dadurch, daß es Oxygen nicht zu binden vermag; die herabgesetzte Fähigkeit des Blutes, Oxygen zu binden, kann also als Maß zur Beurteilung der Menge des erzeugten Methämoglobins gelten. Die oxygenbindende Fähigkeit des Blutes maB ich mit dem Barcroft'schen „Differential-Blutgas - AnalysierApparate“. In das eine Kölbchen des Apparates gab ich $2 \mathrm{ccm}$ natives Blut, in das andere Kölbchen $2 \mathrm{ccm}$ mit Nitritsalz versetztes Blut; das Oxygen wurde mit saponinhaltiger, auf kaltem Wege gesättigter Ferrizyankaliumlösung ausgetrieben. Erst ließ ich die Ferrizyan+ lösung in das native Blut herabfließen und notierte sodann den Druck, welcher dem daraus heraustreibbaren gesamten Oxygen entspricht; sodann lieb ich auch auf der anderen Seite die Ferrizyanlösung herabfließen und notierte sodann die Differenz des Druckes, welche sich aus. 
der Differenz des aus beiden Blutproben heraustreibbaren gesamten Oxygens ergibt; ich brachte dies in Prozenten des Oxygendruckes des nativen Blutes zum Ausdruck. Diese Zahl zeigt, um wieviel Prozent der Oxygengehalt des nativen Blutes im untersuchten Blute abgenommen hat, wie auch ferner, wieviel Prczent vom Oxyhämoglobingehalt des untersuchten Blutes sich in Methämoglobin umwandelte.

1. Kanndergesamte Oxyhämoglobingehalt der roten Blutkörperchen

in Methämoglobin umgewandelt werden?

$\mathrm{Zu} 10 \mathrm{ccm}$ defibrinierten Blutes wird $3,00 \mathrm{ccm}$ physiologische Kochsalzlösung gegeben (a); zu anderen $10 \mathrm{ccm}$ gebe ich $3,00 \mathrm{ccm}$ $\mathrm{n} / 1 \mathrm{KNO}_{2}$-Lösung (b). Nach erfolgter Aufschüttelung notierte ich nach Verlauf einer Stunde und nach Verlauf von fünf Stunden (Zimmertemperatur) in der vorher beschriebenen Weise den Oxyhämoglobingehalt von a) und b). Den Oxyhämoglobingehalt des (a) Blutes für 100 nehmend, fand ich, daß nach einer Stunde der Oxyhämoglobingehalt des (b) Blutes 47, nach fünf Stunden 0 war.

Das $\mathrm{KNO}_{2}$ bewirkt also nach einer gewissen Zeit, daß das gesamte Oxyhämoglobin des roten Blutkörperchens sich in Methämoglobin umwandelt.

2. Besteht ein Unterschied in der Reaktions-

Geschwindigkeit der Nitritwirkung, je nachdem das Nitritsalz auf das im roten Blutkörperchen befindliche Hämoglobin oder auf das gelöste Hämoglobin einwirkt?

$\mathrm{Zu} 20 \mathrm{ccm}$ defibrinierten Blutes gab ich $0,5-2,0 \mathrm{ccm} \mathrm{Na} \mathrm{NO}_{2}-$ Lösung und zerteilte es sodann in zwei Teile; den einen Teil hämolysierte ich, indem ich etwas Saponin hinzugab. Daraufhin notierte ich von Zeit zu Zeit auf vorher beschriebene Weise den Oxyhämoglobingehalt von je $2 \mathrm{ccm}$ beider Teile, indem ich den Vergleich mit dem Oxyhämoglobingehalt von nitritfreiem Blute vornahm.

Die Ergebnisse zweier solcher Versuche lasse ich der leichten Uebersicht wegen im Koordinaten-System aufgezeichnet folgen, indem ich auf der Ordinate die Zeit, auf der Abszisse den Prozentsatz des Oxyhämoglobins (den Oxyhämoglobingehalt des Kontrollblutes mit 100 genommen) verzeichne. Die ausgezogene Kurve bezieht sich auf die roten Blutkörperchen, die punktierte auf das hämolysierte Blut. 
1. $20 \mathrm{ccm} \mathrm{Blut}+0,5 \mathrm{ccm} \mathrm{n} / 1 \mathrm{NaNO}_{2}$

2. $20 \mathrm{ccm} \mathrm{Blut}+2,0 \mathrm{~cm} \mathrm{n} / 1 \mathrm{NaNO}_{2}$

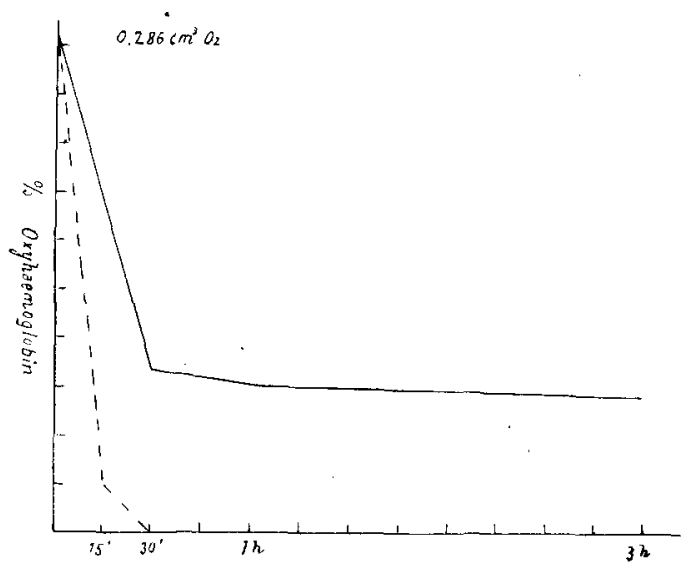

Fig. 1

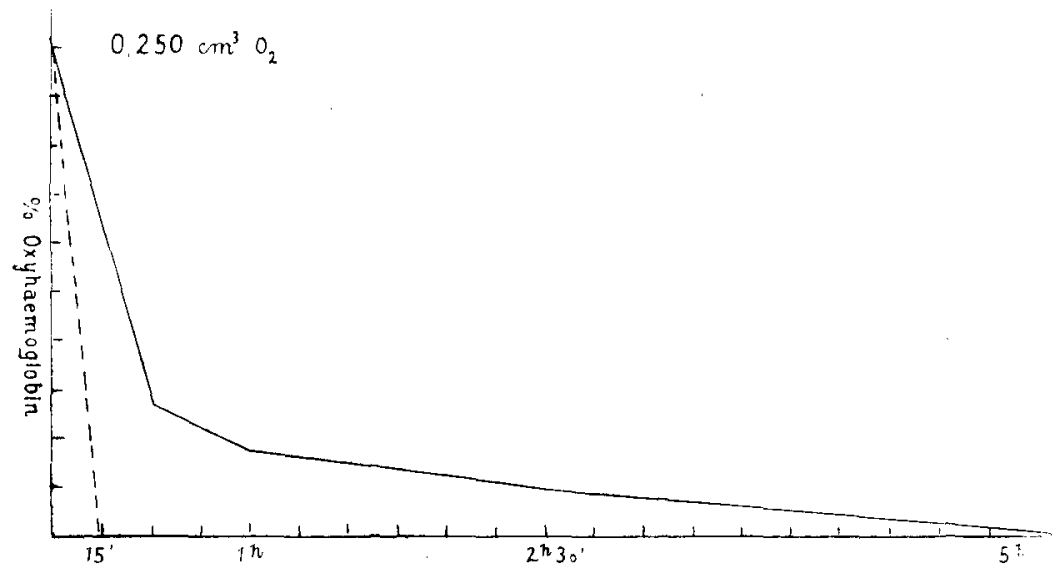

Fig. 2

Aus der Fig. 1 geht hervor, daB im hämolysierten Blute bereits nach einer halben Stunde gar kein Oxyhämoglobin vorzufinden war, in den roten Blutkörperchen dagegen auch nach drei Stunden 30 Proz. des Hämoglobins in Form von Oxyhämoglobin zugegen waren. Im 2. Versuche hat sich im hämolysierten Blute nach $15^{\prime}$ das gesamte Oxyhämoglobin in Methämoglobin umgewandelt, in den Zellen dagegen erfolgte dies jedoch erst nach fünf Stunden.

Aus beiden Kurven ist deutlich zu ersehen, daß unter gleichen Vorbedingungen die Einwirkung des Nitritsalzes be- 
deutend rascher auf das gelöste Hämoglobin, als auf das in der Zellebefindliche Hämoglobin erfolgt.

3. Ueber die hemmende Einwirkung eines Alkalisalzes $(\mathrm{KCl})$ a uf die Nitritreaktion.

Bei der Prüfung der Nitritreaktion durch eine andere Methode habe ich - wie dies weiter unten genau ersichtlich sein wird gefunden, daß gewisse Salze die Einwirkung des Nitrit-Ions auf das rote Blutkörperchen in bedeutendem Maße zu hemmen vermögen. Um etwaigen Kontroversen zu begegnen, schien es mir zweckmäßig, diese hemmende Einwirkung der Salze auch noch durch die exaktere Methode der Gas-Analyse zu untersuchen.

Ich nahm Zellen von defibriniertem Hundeblut, wusch diese an der Zentrifuge mit physiologischer Rohrzuckerlösung und suspendierte sodann in einer etwa anderthalbfachen Menge dieser Rohrzuckerlösung. $\mathrm{Zu} 5 \mathrm{ccm}$ der Suspension gab ich $2 \mathrm{ccm} \mathrm{n} 2 \mathrm{~K} \mathrm{Cl}$-Lösung (a), zu anderen $5 \mathrm{ccm}$ dagegen setzte ich $2 \mathrm{ccm}$ Rohrzuckerlösung hinzu (b); sodann gab ich zu jeder Suspension $0,5 \mathrm{ccm} n 8 \quad \mathrm{NaNO}_{2}$-Lösung. Nach erfolgter Durchschüttelung bestimmte ich von Zeit zu Zeit das Quantum des aus a) und b) austreibbaren gesamten $\mathrm{O}_{2}$; die $\mathrm{O}_{2}$ Kapazität von a) und b) wurde separat mit der Oxygenkapazität von nitritfreiem, ähnlich verdünntem Blut $(5 \mathrm{ccm}$ Suspension $+2,5 \mathrm{ccm}$ Rohrzuckerlösung) gemessen.

Die Darstellung der Daten erfolgt in der gleichen Weise wie vorher. Die ausgezogene Kurve schildert die Umwandlung im System A, die punktierte Kurve jene im System B.

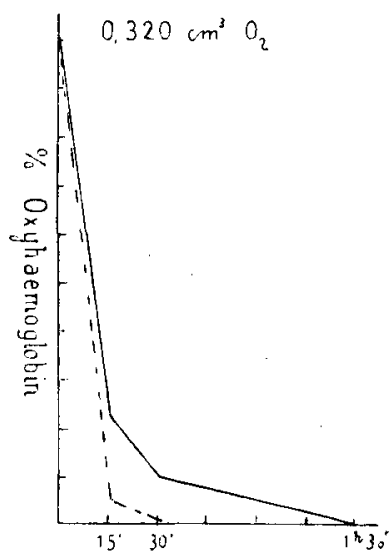

Fig. 3 
Während in der salzfreien Rohrzucker-Suspension nach $15^{\prime}$ bloß 2 Proz. des ursprünglichen Oxyhämoglobingehaltes übrig geblieben ist und auch dieser Rest nach einer halben Stunde in Methämoglobin verwandelt wurde, war in der kaliumchloridhaltigen Suspension nach $15^{\circ}$ noch 24 Proz., nach einer halben Stunde aber noch immer 11 Proz. Oxyhämoglobin zu finden, und hat sich die Reaktion erst nach einer Stunde $30^{\prime}$ ganz vollendet.

Es erscheint also durch die Gasanalyse des Blutes nachgewiesen, dab das Kaliumchlorid die Einwirkung des Nitritsalzes auf die roten Blutkörperchen (schon in einer Konzentration von $\mathrm{n} / 60$ ) beträchtlich hemmt.

e) Einwirkung des Kaliumchlorats auf rote Blutkörperchen und auf hämolysiertes Blut.

Das Kaliumchlorat ist längst unter den Stoffen bekannt, welche das Hämoglobin in Methämoglobin verwandeln. Um diese Einwirkung am einfachsten $z \mathfrak{u}$ demonstrieren, wird zu Blut oder zu Hämoglobinlösung Kaliumchlorat hinzugegeben, und dieses sodann in den $37^{\circ} \mathrm{C}$ Thermostat gesetzt. Nach einigen Stunden wird das lebhaft rote Blut oder Lösung dunkelbraun werden. Das Kaliumchlorat ist, weil es die Blutkörperchen in iso- oder hypertonischer Lösung nicht hämolysiert, ebenfalls zu Permeabilitäts-Untersuchungen für rote Blutkörperchen geeignet; dem raschen Verlauf der Nitriteinwirkung gegenüber ist hier bloß der Nachteil zu berücksichtigen, daß die Einwirkung des Chlorats erst bei erhöhter Temperatur und nach einer längeren Zeit vor sich geht. Die Untersuchung der Chlorateinwirkung habe ich deshalb stets nur behufs Generalisierung der hinsichtlich der Nitriteinwirkung aufgestellten Gesetzmäßigkeiten vorgenommen.

Ich gab zu $20 \mathrm{ccm}$ defibrinierten Rinderbluts $2 \mathrm{ccm} \mathrm{n} / 6 \mathrm{~K} \mathrm{ClO} \mathrm{O}_{3}-$ Lösung, und nachdem ich dieselbe nach Aufschüttelung in zwei Teile geteilt hatte, hämolysierte ich den einen Teil durch Hinzugabe von etwas Saponin; sodann setzte ich beide Proben in $37^{\circ} \mathrm{C}$-Thermostat und bestimmte zeitweise, durch Vergleich mit der Oxygenkapazität von $20 \mathrm{ccm}$.Blut $+2 \mathrm{ccm}$ physiolog. Kochsalzlösung, deren Oxyhämoglobingehalt. Die Darstellung der Daten (Fig. 4) erfolgt in derselben Weise wie vorher; die ausgezogene Kurve bedeutet die Umwandlung der Zellen, die gespaltene Kurve die Umwandlung des hämolysierten Blutes. 


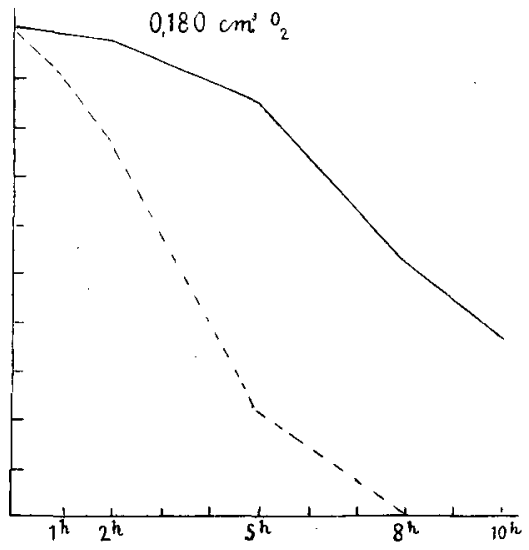

Fig. 4

Aus der Figur erscheint es evident, daß das Chlorat, ebenso wie das Nitritsalz, bedeutend rascher auf das gelöste Hämoglobin, als auf das Zellen-Hämoglobin einwirkt.

Aus der Figur ist ferner zu entnehmen, daß die Chlorateinwirkung in der Zelle nach einer anderen Reaktions-Gleichung sich zu vollziehen scheint, als in der Lösung. Diese Tatsache wird später noch erwähnt werden; zur eingehenden Untersuchung derselben war mir bisher noch keine Gelegenheit geboten.

f) Beeinflussungender Nitrit- und Chloratwirkung.

Die bisher angewandten Methoden haben nur auf die der Prüfung unterzogenen grundlegenden Fragen exakte Aufschlüsse geboten; dieselben können aber, zufolge der Umständlichkeit der Ausführung und der beschränkten Vorbedingungen, nicht als solche Methoden angesehen werden, welche leicht durchgeführt werden können, sobald die bei der eingehenden Untersuchung auftauchenden unzähligen Fragen die zweckentsprechende Lösung erheischen. Die Nitritpermeabilität wollte ich, aus mehreren Rücksichten, unter vielfachen Einwirkungen prüfen. $\mathrm{Zu}$ diesem Zwecke benötigte ich eine leicht ausführbare, allgemein anwendbare Methode; andererseits mufte ich kein Gewicht darauf legen, von der Methode absolute quantitative Ergebnisse zu verlangen, sondern es konnte mir genügen, wenn dieselbe zuverlässige vergleichende Werte gab.

Wird zur stark verdünnten Suspension von mit Rohrzucker oder Traubenzucker ausgewaschenen roten Blutkörperchen eine Lösung von Nitrit- oder Chloratsalz gegeben, so werden dieselben binnen kürzerer 
oder längerer Zeit, je nach der Temperatur oder der Konzentration des. Nitrites oder Chlorates braun werden. Werden mehrere mit der gleichen Menge Zellen-Suspension gefüllte Eprouvetten nebeneinander gesetzt, welcher man sodann sukzessiv größere Mengen Nitrit- (oder Chlorat-) Ionen hinzugibt $(z . B$. in die erste Eprouvette $0,1 \mathrm{ccm} \mathrm{n} 8$-Lösung, in die zweite $0,1 \mathrm{ccm} \mathrm{n} 4$-Lösung usw.), so wird nach einigem Stehen bei vergleichender Beobachtung der Farbe der Suspensionen die von Zeit zu Zeit fortschreitende Reaktion mit Leichtigkeit zu messen sein. Die Brauchbarkeit dieser Methode erscheint durch den Umstand bewährt, daß die durch die oben mitgeteilten Methoden gefundenen Eigentümlichkeiten, namentlich die Abhängigkeit der Reaktionsgeschwindigkeit von der Konzentration des Nitrits oder Chlorates, der Unterschied der Reaktionsdauer des gelösten Hämoglobins und des Zellen-Hämoglobins die hemmende Einwirkung des $\mathrm{KCl}$ (auch auf diese Weise). qualitativ ebenso $z \mathfrak{u}$ konstatieren waren.

An der Hand dieser Methode war es nicht mehr schwierig, den Einflub der verschiedensten Stoffe auf die Nitritpermeabilität zu beobachten.

1. Einwirkung von Salzen, Säuren, Laugen, Alkohol usw. auf die Nitritpermeabilität.

Zu $5 \mathrm{ccm}$ der Lösung des zur Prüfung gezogenen Salzes, Säure usw. gab ich $1 \mathrm{ccm} 10$ fach verdünnte Rohrzucker-Blutzellen-Suspension und $0,1 \mathrm{ccm} \mathrm{n} 8 \mathrm{NaNO}_{2}$-Lösung. Zu gleicher Zeit setzte ich gleiche Mengen Zellensuspension und $\mathrm{NaNO}_{2}$ zu $5 \mathrm{ccm}$ physiologischer Rohrzuckerlösung ( 8 Proz.) und stellte diese als Kontrolle im EprouvettenSchrank neben die übrigen Lösungen. Die in der physiologischen Rohrzuckerlösung suspendierten Zellen wurden allerdings je nach der Frische der verwendeten roten Blutkörperchen usw. etwas verschieden, im allgemeinen aber im Verlaufe einer Minute merklich braun, bis sie in $2^{\prime}-3^{\prime}$ sich maximal braun färbten, worauf sich die Farbe nicht mehr änderte. In in den übrigen Lösungen suspendierten Zellen erfolgte diese Umwandelung teils rascher, teils aber langsamer. Diese Beeinflussungen. waren, wie aus nachstehender Tabelle ersichtlich, zum Teile sehr beträchtlich.

Die Wirkungen der verschiedenen Stoffe sind in drei Tabellen zusammengestellt, je nachdem eine Beschleunigung (A), Hemmung (B), oder aber gar keine Beeinflussung (C) zu konstatieren war. Außer dem Namen des Stoffes sind noch die Konzentrationen angegeben und zwar in $\mathrm{A}$ und $\mathrm{C}$ die minimalen Konzentrationen, die 
noch eine gut beobachtbare Beeinflussung auszuüben vermochten, bei B die maximalen Konzentrationen, in denen noch keine bemerkbare Hemmung oder Beschleunigung eintrat. Um Hypotonie zu vermeiden, wurden die Stoffe, wenn nötig, in 8,1 prozentiger Rohrzuckerlösung angewendet; Hämolyse blieb immer aus. Die Versuche erfolgten bei Zimmertemperatur.

Tabelle V.

A. Beschleunigung. Die $\mathrm{NO}_{2}$-Wirkung ist statt in $2^{\prime}$ schon in $1^{\prime}$ beendet.

\begin{tabular}{c|c|c}
\hline Nr. & Name des Stoffes & $\begin{array}{c}\text { Minimale } \\
\text { Konzentration }\end{array}$ \\
\hline 1 & $\mathrm{Ag} \mathrm{NO}$ & $\mathrm{m} / 200$ \\
2 & $\mathrm{Al} \mathrm{Cl}_{3}$ & $\mathrm{~m} / 2500$ \\
3 & $\mathrm{Hg} \mathrm{Cl}_{2}$ & $\mathrm{~m} / 10000$ \\
4 & $\mathrm{Th}^{\left(\mathrm{NO}_{3}\right)_{3}}$ & $\mathrm{~m} / 25000$ \\
5 & Liquor ferri oxyd. & 0,04 Proz. \\
6 & Rohrzucker & 30 Proz. \\
7 & $\mathrm{H}_{2} \mathrm{SO}_{4}$ & $\mathrm{n} / 2500$ \\
8 & Alanin & $\mathrm{m} / 8$
\end{tabular}

B. Ohne Wirkung.

\begin{tabular}{l|c|c}
\hline Nr. & Name des Stoffes & $\begin{array}{c}\text { Minimale } \\
\text { Konzentrat. }\end{array}$ \\
\hline \hline 1 & Morphinchlorid & 0,5 Proz. \\
2 & Strychninnitrat & 0,2 Proz. \\
3 & Alkohol & $\mathrm{m} / 2$ \\
4 & $\mathrm{Hg}(\mathrm{C} \mathrm{N})_{2}$ & $2 \mathrm{Proz}$. \\
5 & Kaliumferrozyanid & $\mathrm{m} / 2$ \\
6 & Kaliumferrizyanid & $\mathrm{m} / 2$
\end{tabular}

C. Hem mung.

Die $\mathrm{NO}_{2}$-Wirkung ist statt in $2^{\prime}$ erst in $15^{\prime}$ beendet.

\begin{tabular}{c|c|c}
\hline \hline Nr. & Name des Stoffes & $\begin{array}{c}\text { Minimale } \\
\text { Konzentrat. }\end{array}$ \\
\hline \hline 1 & $\mathrm{~K} \mathrm{Cl}, \mathrm{KJ}, \mathrm{KBr}$, & \\
& $\mathrm{K} \mathrm{NO}_{3}, \mathrm{~K} \mathrm{SCN}$ & $\mathrm{m} / 10$ \\
2 & $\mathrm{~K}_{2} \mathrm{~S} \mathrm{O}_{4}$ & $\mathrm{~m} / 1$ \\
3 & Natriumbenzoat & $\mathrm{m} / 50$ \\
4 & $\mathrm{~K} \mathrm{Cl} \mathrm{O}_{3}$ & $\mathrm{~m} / 1$ \\
5 & $\mathrm{Ammoniak}$ & $\mathrm{m} / 2000$ \\
6 & $\mathrm{KOH}$ & $\mathrm{m} / 2000$
\end{tabular}

Aus der Tabelle geht hervor, daB Säuren sowie hydrolysierende Salze von mehrwertigen Kationen $\left(\mathrm{AlCl}_{3}\right.$, $\mathrm{Th}\left(\mathrm{NO}_{3}\right)_{4}$, ferner Kolloide positiver Ladung (Ferrihydroxyd), alles Stoffe, welche die roten Blutkörperchen $z u$ agglutinieren vermögen, die Nitriteinwirkung, auch in bereits sehr beträchtlicherVerdünnung, bedeutend beschleunigen. Demgegenüber sind Laugen, a uch in bereits sehrbeträchtlicher Verdünnung, in bedeutendem 
Maße hemmende Faktoren. Desgleichen sind in größerer Konzentration auch die einwertige Anionen enthaltendenAlkalimetallsalzevonbedeutender hemmender Einwirkung; das Kaliumchlorat wirkt auch in grober Konzentration blob in unbedeutendem Maße hemmend, und die Alkalimetallsalze, welche zwei- und dreiwertige Anionen enthalten, vermögen kaumoder auch gar nicht die Reaktion zu beeinträchtigen. Alanin ist in größerer Konzentration von beschleunigender Wirkung; sehr stark konzentrierter Rohrzucker wirkt ebenfalls beschleunigend. Das Strychninnitrat (etwas hydrolytisch sauer) beschleunigt ein wenig; Natriumbenzoat (etwas hydrolytisch alkalisch) wirkt bedeutend hemmend; $Q$ uecksilberzyanid, Morphinchlorid, Alkohol haben keinen EinfluB auf die Reaktion.

Auf die Bedeutung dieser Tatsachen werde ich im Laufe der theoretischen Erörterungen des näheren eingehen. Einstweilen möchte ich bloß darauf aufmerksam machen, daß nach diesen Daten die Nitriteinwirkung nur durch Stoffe mit elektrischer Ladung bedeutend beeinträchtigt wird.

Nicht-Elektrolyte vermögen, auch wenn es Narkotika oder Alkaloide sind, nur bei grober Konzentration und auch dann in unbedeutendem Maße die Reaktion zu beeinflussen, das gleiche gilt für Salze, welche nicht elektrolytisch dissoziiert sind $\left(\mathrm{Hg}(\mathrm{CN})_{2}\right)$. Die mit positiver Elektrizität geladenen Teilchen $\left(\mathrm{H}^{+}, \mathrm{Th}++++\right)$ wirken beschleunigend, die negativ geladenen Teilchen wirken hemmend. Von den Anionen hemmen die einwertigen am meisten. Das zweiwertige Anion $\mathrm{SO}_{4}$ hemmt nur in größeren Konzentrationen, die drei- bzw. vierwertigen Anionen Ferrizyan"' und Ferrozyan" sind noch in $\mathrm{m} / 2$ Konzentration wirkungslos. Unter den einwertigen Anionen nimmt das Chlorat' einen besonderen Platz ein, da es nur in sehr großen Konzentrationen hemmt. Auch auf diese Eigentümlichkeiten werden wir später zurückkommen.

2. Aehnliche Prüfungen mit Kaliumchlorat.

Den vorherigen ähnliche Versuche nahm ich über die Einwirkung des Kaliumchlorats vor. Wie bereits erwähnt, vollzieht sich diese Einwirkung bei Zimmertemperatur sehr langsam, und auch bei $37^{\circ} \mathrm{C}$ (je nach der Konzentration des Chlorats) in den Zeiträumen von einer Viertelstunde bis zu 24 Stunden. Die Chloratversuche erfolgten des- 
halb in einem $37^{\circ} \mathrm{C}$-Thermostat; zu $5 \mathrm{ccm}$ der Lösung des Stoffes, dessen Einwirkung der Prüfung unterzogen wurde, gab ich $1 \mathrm{ccm}$ Blutzellensuspension und $1 \mathrm{ccm} \mathrm{n} 6 \mathrm{~K} \mathrm{ClO}_{3}$-Lösung; als Grundlage des Vergleichs wurde auch hier das aus achtprozentiger Rohrzuckerlösung $+1 \mathrm{ccm}$ Blutkörperchen $+1 \mathrm{ccm} \mathrm{n} 6 \mathrm{KClO}_{3}$ bestehende System genommen. Die bewirkte Beschleunigung oder Hemmung war, zufolge der verlängerten Reaktionsdauer, bei weitem anschaulicher zu beobachten, als bei der Nitriteinwirkung.

Zur Prüfung wurden die bereits bei der Beschreibung der Nitritreaktion angeführten Stoffe genommen. Ich halte es für überflüssig, diese in einer separaten Tabelle anzuführen, denn das Ergebnis war ganz dem vorherigen gleich. Die der Prüfung unterzogenen Stoffe beeinträchtigen.die Einwirkung des Kaliumchlorates auf das Hämoglobin der roten Blutzelle ganz in derselben Weise, wie sie die Nitritreaktion beeinträchtigen.

Die Tatsache, daß sich die Chlorateinwirkung erst bei erhöhter Temperatur in längerer Dauer vollzieht, läßt die wichtige Frage aufkommen, ob die Aufnahme des Chlorats, oder aber die ChloratHämoglobin-Reaktion die erhöhte Temperatur und die längere Dauer erfordert? Es ist mit zwei Möglichkeiten zu rechnen: daß nämlich das Chlorat-Ion bei Zimmertemperatur sofort in die Zelle dringt, jedoch erst bei erhöhter Temperatur usw. auf das Hämoglobin einwirkt; oder aber das Chlorat wird bei gewöhnlicher Temperatur von der Zelle gar nicht aufgenommen. Diese Frage behandelte ich folgendermaßen: Ich gab zu $5 \mathrm{ccm}$ Rohrzucker-Blutzellen-Suspension $2 \mathrm{ccm} \mathrm{n} 6 \mathrm{~K} \mathrm{ClO}_{3}$-Lösung und teilte dieselbe nach erfolgter Aufschüttelung in zwei Teile. Der eine Teil blieb unberührt (a), den anderen Teil zentrifugierte ich nach $5^{\prime}-10^{\prime}$ und wusch ihn mehrfach mit achtprozentiger Zuckerlösung solange, bis sich die Waschflüssigkeit nach Kochen mit Schwefelsäure und Ferroammoniumsulfat bei Hinzugabe von $A g \mathrm{NO}_{3}$ nicht trübt - ein Zeichen dafür, daB sie kein Chlorat enthielt (b). Sodann gab ich beide Suspensionen in den $37^{\circ} \mathrm{C}$-Thermostat. Wurde das Chlorat bei der Zimmertemperatur aufgenommen, so muß bei b die Chlorateinwirkung während der gleichen Dauer erfolgen wie bei a, denn mit Zuckerlösung können bekanntlich Elektrolyte aus der roten Blutzelle nicht ausgewaschen werden. Ich habe nun gefunden, daß während a nach $30^{\prime}$ dunkelbraun wurde, $b$ auch nach Stunden noch rot blieb. Gab ich anstatt n $6 \mathrm{KClO}_{3}$ zur Zellensuspension $\mathrm{n} 1 \mathrm{KClO}_{3}$, so wurde a bereits 
nach $10^{\circ}$ dunkelbraun, b dagegen blieb auch jetzt nach Stunden unverändert. Die Temperatur beeinträchtigt demnach nicht nur die Chloratreaktion, sondernauch die Chlorataufnahme; die Aufnahmedes Chlorates erfolgterst bei erhöhter Temperatur.

g) Eingehende Prüfungen über die Einwirkung der Salze.

In Tabelle $\mathrm{V}$ wurde ersichtlich gemacht, daß einige Salze in der Konzentration $\mathrm{m} / 2$ die Nitriteinwirkung bedeutend hemmen, einige andere aber dieselbe nicht beeinträchtigen. Zufolge der bedeutenden hemmenden Einwirkung dieser großen Salzkonzentration waren kleinere Abweichungen in der Einwirkung der einzelnen Salze nicht wahrzunehmen; sobald aber kleinere Konzentrationen des zur Prüfung genommenen Salzes verwendet werden, kann auch bei solchen Salzen ein Unterschied der Einwirkung beobachtet werden, welche in der Tabelle $\mathrm{V}$ als von gleicher Einwirkungskraft bezeichnet wurden.

\section{Einwirkung der Salze}

gleichen Kations und verschiedenen Anions.

Die hemmende Einwirkung der Salze ist schon in ihrer $\mathrm{m} / 100$ Lösung wahrnehmbar, in ihrer $\mathrm{m} / 50$ - Lösung aber bereits ausdrücklich vorhanden. Die nachfolgenden Versuche erfolgten derart, daß ich zu $5 \mathrm{ccm} \mathrm{m} / 100$ - oder $\mathrm{m} / 50$-Lösung ${ }^{1}$ ) der zur Prüfung genommenen verschiedenen Salze $1 \mathrm{ccm}$ Rohrzucker-Blutzellen-Suspension gab und in einem Eprouvettenschrank nebeneinander setzte; zum Vergleiche hat stets das aus $5 \mathrm{ccm}$ achtprozentigen Rohrzuckers und 1 ccm Blutzellen-Suspension bestehende System gedient. Sodann habe ich möglichst rasch in jede Eprouvette drei Tropfen $\mathrm{n} 8 \mathrm{Na}$ triumnitrit-Lösung gegeben und beobachtete, indem ich die Zeit notierte, nach Durchschüttelung das Eintreten der Farbenänderungen. Ich prüfte die folgenden Salze: $\mathrm{K} \mathrm{Cl}, \mathrm{KJ}, \mathrm{KSCN}, \mathrm{KNO}_{3}, \mathrm{~K}_{2}(\mathrm{COO})_{2}$, $\mathrm{K}_{2} \mathrm{SO}_{4}$. Zwischen dem Grade der Einwirkung dieser Salze waren konstante und gut wahrnehmbare Zeitunterschiede. So zum Beispiel haben sich aus den mit m/100-Salzlösungen vorgenommenen Prüfungen folgende Daten ergeben: in der Rohrzuckerlösung ist nach 1' die Farbenveränderung gut zu beobachten; beinahe so rasch ist dies

1) Diese Lösungen wurden derart angefertigt, daß ich den Elektrolyt in $\mathrm{m} / 100$ bis $\mathrm{m} / 50$. Konzentration in achtprozentiger Rohrzuckerlösung löste. 
im Sulfat der Fall; im Chlorid und Jodid ist die Farbenveränderung in $2^{\prime}$, im Nitrat erst nach $3^{\prime}$, im Oxalat in $20^{\prime}$, im Rhodanid in $30^{\prime}$ erfolgt.

Bei Salzlösungen von $\mathrm{m} / 50$ und Verwendung von vier Tropfen Nitrit n 8 ist: Rohrzucker und Sulfat binnen $2^{\prime}$, Chlorid, Jodid nach $3^{\prime}$, Nitrat nach $5^{\prime}$, Oxalat nach $15^{\prime}$ braun geworden; Rhodanid blieb nach $30^{\circ}$ noch rot.

In der hemmenden Einwirkung der Anionen ist also entschieden eine gewisse Reihenfolge konstatierbar. Am wenigsten hemmt Sulfat, am stärksten Rhodanid; daß Ferro- und Ferrizyan sogar in einer Konzentration von $\mathrm{m} / 2$ vollkommen wirkungslos ist, wurde bereits bei der Tabelle $V$ gesehen. Die Reihenfolge der Anionen, welche auf die Reaktion des Nitrit-Blutzellen-Hämoglobins einwirken, ist also folgende: Ferrozyan, Ferrizyan < Sulfat $<$ Chlorid, Jodid $<$ Nitrat $<$ Oxalat $<$ Rhodanid.

\section{Einwirkung von Salzen}

mit gleichem Anion und verschiedenem Kation.

$\mathrm{Zu}$ diesen Versuchen wurden die Nitrate des Kaliums, Natriums, Lithiums, Rubidiums, Ammoniums, Kalziums und Bariums genommen. Wird zu $5 \mathrm{ccm}$ der $\mathrm{m} / 8$-Lösungen dieser Nitrate $1 \mathrm{ccm}$ Zellensuspension und $1 \mathrm{ccm}$ Nitrit $\mathrm{n} / 8$ gegeben, so vollzieht sich, mit Ausnahme des Ammoniumnitrates, in den übrigen Salzen die Farbenveränderung in gleicher Zeit. Die Suspension mit $\mathrm{H}_{4} \mathrm{~N}\left(\mathrm{NO}_{3}\right)$ ist aber viel rascher (nach $1^{\prime}$, die übrigen erst nach 15') braun geworden; nach Zentrifugieren der Suspension stellte sich aber heraus, daß dieselbe stark hämolytisch ist.

In Versuchen mit Salzlösungen $\mathrm{m} / 100$ fand ich, dab $\mathrm{K}, \mathrm{Na}, \mathrm{Ru}$, $\mathrm{Li}, \mathrm{H}_{4} \mathrm{~N}$ in gleichem Maße hemmen; $\mathrm{Ca}$ und $\mathrm{Ba}$ hemmen etwas stärker.

Wird in Betracht genommen, daB in den Versuchen mit $\mathrm{m} / 8$ Lösungen das abweichende Verhalten des $\mathrm{H}_{4} \mathrm{~N}$-Ions darin seine Begründung hatte, daß das Ion hämolytisch war (denn in den Versuchen mit $\mathrm{m} / 100$ - Lösungen, wo also das $\mathrm{H}_{4} \mathrm{~N}$ - Ion in nicht hämolysierender Konzentration gegeben wurde, verhielt es sich den übrigen gleich); daß ferner die Salze $\mathrm{Ca}$ und $\mathrm{Ba}$ deshalb in etwas größerem MaBe hemmend wirkten, weil sie das zweifache Quantum vom Anion enthielten, so kann ausgesprochen werden, daB die Einwirkung der verschiedenen Kationen auf die Nitritzellen-Hämoglobin- 
Reaktion sich nicht von einander unterscheidet. Dies besagt gleichzeitig, daB die Einwirkung der Salze in der Einwirkung ihrer Anionen besteht, und daB die Kationen wirkungslos sind.

3. Versuche zur Aenderung der Anionen-Reihenfolge.

Einer Erwägung zufolge, die ich im theoretischen Teile erwähnen werde, versuchte ich, die oben beschriebene Reihenfolge der Anionen dadurch zu ändern, daß ich den $\mathrm{H}^{+}$- Gehalt des Suspensionsmediums änderte. Bei einer Reihenfolge der Anionen von $\mathrm{m} / 100-, \mathrm{m} / 50-, \mathrm{m} / \mathbf{8}^{-}$ Konzentrationen gab ich zu $5 \mathrm{ccm}$ Salzlösung $0,1-1 \mathrm{ccm} \mathrm{n} 50 \mathrm{H}_{2} \mathrm{SO}_{4}$ bzw. $0,1-0,5 \mathrm{ccm} \mathrm{n} / 100 \mathrm{~K} \mathrm{OH}$, und beobachtete sodann die AnionenReihenfolge; ich habe also die Reaktion des Mediums soweit geändert, als es, ohne Gefahr der Hämolyse, nur möglich war. Abgesehen vom Platzwechsel zweier nebeneinander stehender Anionen (im stark sauer reagierenden Medium nicht Sulfat < Chlorid, sondern Chlorid < Sulfat), war in der Anionenreihe eine Aenderung nicht wahrzunehmen. Die Reihenfolge der hemmend einwirkenden Anionen hängt also vom Hydrogeniongehalt des Mediums nicht ab.

\section{Abhängigkeit der. Einwirkung}

der Anionen von der Konzentration des Anions.

Werden die Salze in noch verdünnteren Lösungen als $\mathrm{m} / 100$ angewendet, so wird man wahrnehmen, daß dieselben in gewissen Konzentrationen nicht hemmend einwirken, sondern vielmehr die Nitrit-Zellen - Hämoglobin - Reaktion beschleunigen ; jener Grad der Konzentration, welcher diese entgegengesetzte Wirkung erzeugt, ist je nach den geprüften Anionen verschieden.

$\mathrm{Da}$ ich hier sehr minimale Salzkonzentrationen auf ihre Wirkung hin in Prüfung nahm, habe ich bei diesen Experimenten mit möglichster Sorgfalt ausgewaschene rote Blutkörperchen verwendet, damit die suspendierende Rohrzuckerlösung die Elektrolyte des Serums auch nicht in Spuren enthalte. Ich wusch die Zellen des defibrinierten Blutes 8-10 fach mit Rohrzuckerlösung an der Zentrifuge solange, bis in der Waschflüssigkeit Chlor auch in Spuren nicht mehr nachweisbar war. Ich machte die Wahrnehmung, daß bei Erlangung dieses Grades der Elektrolytlosigkeit die roten Blutkörperchen stets teilweise agglutinierten, was mich bei den späteren Versuchen bewog, das Eintreten der Agglutination als 
Zeichen der genügend ausgefallenen Waschung zu betrachten. Gab ich zur solcherart agglutinierten Zellensuspension eine.Spur von Elektrolyt, dann verteilten sich die Zellen wieder als gleichmäßige Suspension.

( $\mathrm{Da}$ ich bei diesem meines Wissens bisher unbekannten Phänomen weiter nicht verweile, will ich hier ganz kurz über das Wesen desselben sprechen. Diese Agglutination der roten Blutkörperchen reprä-. sentiert eigentlich den Grenzfall der Säure-Agglutinationen; ich fand nämlich, daB die Säure-Agglutination der suspendierten Zellen irgend einer Elektrolytlösung bei einer umso kleineren $\mathrm{H}^{+}$- Konzentration erfolgt, je verdünnter die Elektrolytlösung ist. Die in physiologischer Kochsalzlösung suspendierten Zellen agglutinieren bei Hinzugabe eines. bestimmten Quantums Mineralsäure, reagieren aber nicht bei Einführung von $\mathrm{CO}_{2}$-Gas. Die mit Rohrzuckerlösung ein- bis zweimal ausgewaschenen Zellen aber werden bei Einführung von $\mathrm{CO}_{2}$-Gas sogleich agglutinieren. Werden nun nach vielfachem Auswaschen auch die Spuren der Ionen aus dem Suspensionsmedium entfernt, so wird auch bei neutraler Reaktion Agglutination zustande kommen.

Es ist eine aus der Kolloidchemie bekannte Erscheinung, daß wenn aus der Lösung eines hydrophilen Kolloids die darin befindlichen Elektrolyte durch Dialyse vollkommen entfernt werden, die Kolloidlösung instabil wird. Nachdem es an der aufladenden Einwirkung der aus der Lösung absorbierten lonen, der zufolge die mit homogener Elektrizität gefüllten Teilchen einander abstoben, fehlt, kleben sich die Teilchen aneinander und kommt dadurch Koagulation zustande. Es ist bekannt, daß die in Elektrolytlösung suspendierten roten Blutkörperchen anodisch, d. h. von negativer Ladung sind; ihre Stabilität wird dann am kleinsten sein, wenn diese negative Ladung durch eine Säure, deren Kation adsorbiert wurde, neutralisiert wird; die hierzu benötigte $\mathrm{H}^{+}$-Konzentration aber mag umso kleiner ausfallen, je schwächer die negative Ladung der Zellenoberfläche ist. Sobald diese Ladung - zufolge Entfernung der Elektrolyte - aufhört, muß die Agglutination, auch wenn keine Säure vorhanden ist, von selbst eintreten.)

Den sehr verdünnten Salzlösungen gab ich die mit Rohrzuckerlösung verdünnte Suspension der solcherart ausgewaschenen roten Blutkörperchen hinzu; sodann habe ich, nach Zutropfen von etwas Nitritlösung, den Zeitpunkt der Farbenveränderung notiert. Zum Vergleiche wurde elektrolytfreie Rohrzucker-Suspension genommen. Der Verlauf eines solchen Versuchs war folgender: Ich gab in sechs neben- 
einander stehende Probiergläschen je $5 \mathrm{ccm}$ folgender Lösungen: 1. Achtprozentigen Rohrzucker, 2. achtprozentigen Rohrzucker, enthaltend $\mathrm{n} / 100000 \mathrm{~K} \mathrm{Cl}$, 3. Rohrzucker, $\mathrm{n} / 10000 \mathrm{~K} \mathrm{Cl}$, 4. Rohrzucker, $\mathrm{n} / 1000 \mathrm{~K} \mathrm{Cl}, 5$. Rohrzucker, $\mathrm{n} / 100 \mathrm{~K} \mathrm{Cl}$, 6. Rohrzucker, $\mathrm{n} / 10 \mathrm{~K} \mathrm{Cl}$. Sodann gab ich jeder Lösung $1 \mathrm{ccm}$ Blutzellen-Suspension und schließlich zwei Tropfen n 8 Natriumnitrit - Lösung hinzu. Die Farbenveränderung war in 1 und 2 nach $3^{\prime}$, in 3 und 4 nach $2^{\prime}$, in 5 nach $5^{\prime}$ wahrzunehmen; 6 blieb auch nach $10^{\prime}$ rot. Es folgt hieraus, daB das $\mathrm{KCl}$ die Nitriteinwirkung in Konzentrationen zwischen $\mathrm{n} / 10000$ bis $\mathrm{n} / 1000$ beschleunigt; darunter vermag es die Nitriteinwirkung nicht zu beeinträchtigen, darüber wirkt es hemmend ein.
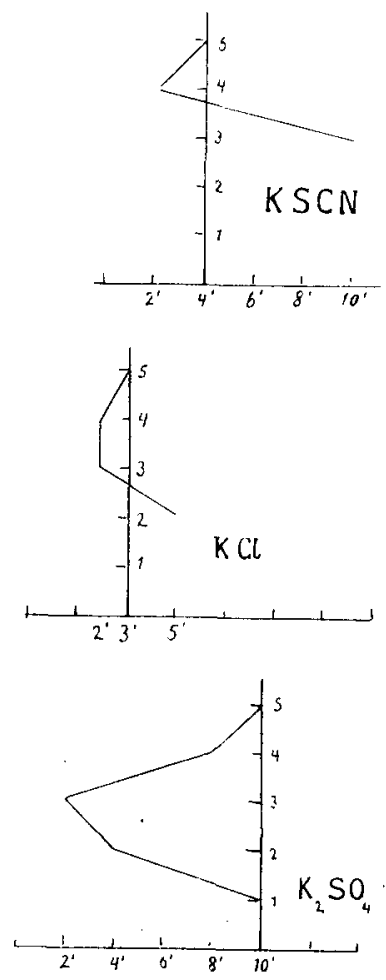

Fig. 5

Das derartige Verhalten des $\mathrm{KCl}, \mathrm{KSCN}$ und $\mathrm{K}_{2} \mathrm{SO}_{4}$ illustriere ich hier im Koordinatensystem (Fig. 5). Auf der Ordinate verzeichnete ich den Zeitpunkt der eingetretenen Farbenveränderung (in $\mathrm{Mi}$ nuten); der Mittelpunkt der Ordinate ist jener Zeitpunkt, in welchem die Reaktion des vollständig elektrolytfreien Mediums abzulesen war; 
die vom Zentrum rechts fallenden Punkte bezeichnen demnach die Hemmung, die links fallenden Punkte die Beschleunigung. Auf der Abszisse trug ich, in nach aufwärts fallendem Werte, den Logarithmus der Konzentration des Salzes auf $(\mathrm{m} / 10=1, \mathrm{~m} / 100=2$ usw.).

Aus den Figuren ist ersichtlich, daß das SCN-Ion in Konzentration $\mathrm{n} / 10000$ beschleunigt, in höherer Konzentration bereits hemmt ; das $\mathrm{Cl}$ - Ion wirkt auch in Konzentration $\mathrm{n} / 1000$ noch beschleunigend und hemmt bloß in einer diese an [Stärke übersteigenden Konzentration; das $\mathrm{SO}_{4}$-Ion beschleunigt bis zur $\mathrm{n} / 10$-Konzentration und wirkt auch noch in $\mathrm{n} / 10$-Konzentration nicht hemmend ein. Die Reihenfolge ist also auch hier $\mathrm{SO}_{4}<\mathrm{Cl}<\mathrm{SCN}$.

\section{h) Einwirkung von Nitrit}

in Gegenwart einiger Salze auf hämolysiertes Blut und auf die Lösung von kristallisiertem Hämoglobin.

Auf Grund experimenteller Ergebnisse wurde oben bereits ausgeführt, daß die Nitrit-Hämoglobin-Reaktion sich in hämolysiertem Blute rascher als im nativen nicht hämolysierten Blute vollzieht. Nachstehend bespreche ich meine Versuche, durch welche ich die letztbeschriebenen verschiedenen Einflüsse der Nitritreaktion (Salze usw.) auf das hämolysierte Blut untersuchte.

Der Verlauf dieser Untersuchungen war derselbe, wie jener der unter Punkt $f$ und $g$ angeführten Experimente mit den roten Blutkörperchen. Der Unterschied bestand nur darin, daß zu $5 \mathrm{ccm}$ der Lösung des Stoffes, dessen Einfluß den Gegenstand der Prüfung bildete, nicht $1 \mathrm{ccm}$ Blutzellen - Suspension, sondern $1 \mathrm{ccm}$ entsprechend verdünntes hämolysiertes Blut gegeben wurde. Letzteres wurde erzeugt, indem ich die mit achtprozentiger Rohrzuckerlösung ausgewaschenen Zellen $10-20$ fach mit destilliertem Wasser verdünnte; hierauf erfolgte vollständige Hämolyse, die ich in vielen Fällen durch Hinzugabe von etwas Saponin noch beschleunigte. $\mathrm{Zu}$ diesen Systemen gab ich sodann $2-3$ Tropfen n 50 Natriumnitrit.

Das Ergebnis dieser Experimente kann ich hier kurz zusammenfassen. Jene Stoffe, deren Einwirkung auf die roten Blutkörperchen in der Tabelle $\mathrm{V}$ zusammengefaßt wurde, wirken, soweit dies die Richtung und den Unterschied des Einflusses betrifft, auch auf das hämolysierte Blut fast in gleicher Weise ein. Die Säuren also beschleunigen, die Laugen hemmen, die einwertigen Anionen (Chlor ausgenommen) hemmen, das Alanin, der Rohrzucker, das Strychnin, das 
Morphin, Alkohol beeinträchtigen in der gleichen Richtung und in dem gleichen Maße.

Die Einwirkung der Salze auf die gelösten Blutkörperchen der Einwirkung auf die Zellen gegenüber - weist folgende Unterschiede auf: Die hemmende Einwirkung ist erst bei $\mathrm{m} / 8$ oder noch höherer Konzentration ausdrücklich bemerkbar. Die Anionenreihe ist nicht vollkommen mit der bei den Zellen geltenden Anionenreihenfolge identisch.

Die Reihenfolge bei den Zellen war:

Sulfat $<$ Chlorid, Jodid $<$ Nitrat $<$ Oxalat $<$ Rhodanid,

bei den hämolysierten Zellen dagegen ist die Reihenfolge

Chlorid $<$ Oxalat $<$ Sulfat $<$ Nitrat $<$ Jodid $<$ Rhodanid,

stellenweise also übereinstimmend, anderwärts abweichend. Die Einwirkung des Ferri- und Ferrozyankaliums konnte hier nicht untersucht werden, weil diese das gelöste Hämoglobin auch selbst in Methämoglobin verwandeln.
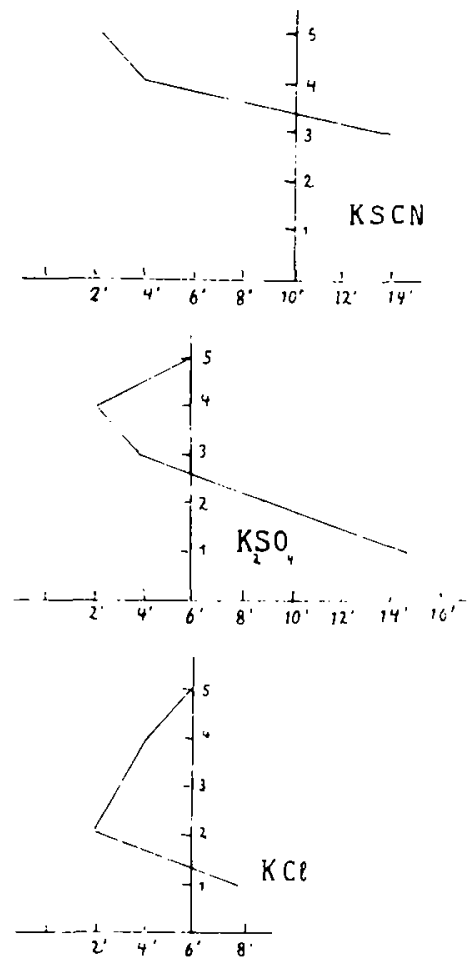

Fig. 6 
Die Einwirkung der Anionen ist auch hier von der Konzentration des Anions abhängig: es beschleunigt bei den minimalen Konzentrationen und hemmt bei den höheren. Des Vergleiches wegen habe ich die mit der lonen - Konzentration vorgehende Veränderung der $\mathrm{Cl}^{\text {, }}$, $\mathrm{SO}_{4}{ }^{\prime \prime}$ und $\mathrm{SCN}^{\prime}$-Einwirkung auf die Nitritreaktion der gelösten Blutkörperchen in Fig. 6 in derselben Weise dargestellt, wie dies weiter oben mit der Einwirkung auf die Zellen erfolgte.

Die hemmende Einwirkung des Rhodan-Ions ist also auch hier bei $\mathrm{n} 1000$-Konzentration bereits bemerkbar; das Sulfat wirkt hier in n 10 - Lösung bedeutend hemmend ein, wogegen es dort wirkungslos blieb; das Chlor hemmt hier erst in $\mathrm{n} 10$-Konzentration, dort war dies bereits bei $\mathrm{n} 100$-Lösung der Fall. Die Reihenfolge war dort $\mathrm{SO}_{4}<\mathrm{Cl}<\mathrm{SCN}$, hier ist sie $\mathrm{Cl}<\mathrm{SO}_{4}<\mathrm{SCN}$.

Zwischeii der Einwirkung der Nitrate von $\mathrm{K}, \mathrm{Na}, \mathrm{Li}, \mathrm{Ru}, \mathrm{H}_{4} \mathrm{~N}$, $\mathrm{Ca}$ und $\mathrm{Ba}$ ist in äquimolekularer Konzentration auch hier kein wesentlicher Unterschied wahrzunehmen.

Um die Reaktion frei vom Einflusse der anläßlich der Hämolyse in die Lösung gelangenden übrigen Zellenbestandteile beobachten zu können, habe ich über die Einwirkung der Salze den obigen ähnliche Versuche mit reinem (kristallisiertem) Hämoglobin angestellt. Das Hämoglobin stellte ich aus Pferdeblut in der üblichen Weise dar; ich zentrifugierte defibriniertes Pferdeblut und wusch die Zellen an der Zentrifuge dreimal mit physiologischer Kochsalzlösung, sodann gab ich ein gleiches Quantum ausgekochtes destilliertes Wasser hinzu. Die solcherart hämolysierte Lösung ließ ich auf $0^{\circ} \mathrm{C}$ abkühlen und gab $1 / 4$ Volum auf $0^{\circ} \mathrm{C}$ abgekühlten 96 prozentigen Alkohol dazu; das Gemisch ließ ich 24 Stunden lang in einem Eisbade von $0^{\circ} \mathrm{C}$ stehen. Während dieser Zeit kristallisierte ein Teil des Oxyhämoglobins. Nachdem ich die Kristalle durch Zentrifugieren in auf $0^{\circ} \mathrm{C}$ abgekühlten Gefäßen von der Lösung isolierte, ließ ich dieselben mit etwas destilliertem Wasser bei $38^{\circ} \mathrm{C}$ wieder auflösen. Sodann kühlte ich die Lösung ab und kristallisierte sie wieder, indem ich Alkohol gleichen Volums hinzugab. Nach 24 stündigem Stehen auf $0^{\circ} \mathrm{C}$ zentrifugierte ich, löste die Kristalle in destilliertem Wasser auf und erhielt solcherart eine reine Oxyhämoglobin-Lösung.

In dieser Oxyhämoglobin-Lösung nimmt die Nitriteinwirkung denselben Verlauf, wie dies im hämolysierten Bluteder Fall ist. Die hemmende Einwirkung derAnionen, die Reihenfolgeder Anionen, die Wirkungslosigkeit der Nichtelektrolyte und der Kationen, die 
Säure-, die Laugeneinwirkung usw. ist ebenso wahrzunehmen wie im hämolysierten Blute.

\section{III.}

\section{Untersuchungen über die Permeabilität des Ferrizyankaliums.}

Es ist eine altbekannte Tatsache, daß das Ferrizyankalium, welches das Hämoglobin des hämolysierten Blutes momentan in Methämoglobin umwandelt, auf das Hämoglobin des unversehrten roten Blutkörperchens nicht einzuwirken vermag. Hop pe-Seyler, der erste, der auf diesen Umstand aufmerksam machte, legte dies dahin aus, daß er die Hypothese aufstellte, daß das in der Zelle befindliche Hämoglobin (das Arterin) sich vom gelösten Hämoglobin $\mathrm{che} \mathrm{m}$ is $\mathrm{ch}$ unterscheide. Seitdem man sich aber mit den Erscheinungen der Permeabilität eingehender befaßt, wird diese auch sonst unbegründete Hypothese nicht mehr akzeptiert, sondern die Wirkungslosigkeit des Ferrizyankaliums wird derart ausgelegt, daß dasselbe nicht in die Zelle eindringt; deshalb ist es auf das mit dem gelösten Hämoglobin identische ZellenHämoglobin ohne Wirkung. Die Bedingungen dieser „Impermeabilität“ wurden aber bislang keiner Prüfung unterzogen.

Das Ferrizyankalium bildet also (nebst dem Ferrozyankalium) einen scharfen Gegensatz zu den Nitriten und Chloraten, welche, wie nachgewiesen wurde, auf das gelöste und auf das Zellen-Hämoglobin in fast gleicher Weise einwirken. Ich unternahm sehr viele Versuche, um über das Wesen dieser Verschiedenheit Klarheit zu schaffen. Ich setzte die roten Blutkörperchen den mannigfaltigsten chemischen und physikalischen Einwirkungen aus, damit sie für das Ferrizyankalium permeabel wurden, ohne daß ich dessen Zeichen, das Braunwerden der roten Suspension, konstatieren konnte. Speziell habe ich die Blutkörperchen mit hämolytischen Agentien (Alkohol, Chloroform, Saponin) bis zu den sogen. hämolytischen Grenzkonzentrationen dieser Stoffe behandelt, auch gänzlich erfolglos. Endlich gelang es mir einen Stoff zu finden, unter dessen Einwirkung das Ferrizyankalium fast momentan auf das Zellen-Hämoglobin einwirkt, ohne daß inzwischen Hämolyse entstanden wäre.

Die Beurteilung des Einflusses des Ferrizyankaliums erfolgte dann durch Vornahme gasanalytischer Messungen. Wird der Suspension roter Blutkörperchen Ferrizyankalium hinzugegeben, kann -- solange die Zellen nicht irgendwie hämolysiert werden - im Barcroft'schen Apparat keinerlei Freiwerden von Oxygen nachgewiesen werden, mag 
die Konzentration des Ferrizyankaliums noch so stark sein. Wird

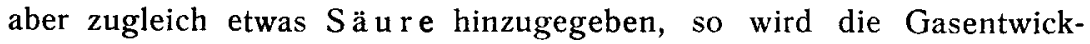
lung sogleich eintreten, trotzdem die angewendeten Säurequantitäten allein, ohne Ferrizyankalium, kein Oxygen aus dem Blut herauszutreiben vermögen.

Zum Beweis dessen, daß die der Hämoglobin-Lösung hinzugegebene Säure allein keine Oxygenbildung hervorruft, mag folgender Versuch dienen: Ich gab in das eine (linksseitige) Gefäß des Differential-Gas-Analysier-Apparates $2 \mathrm{ccm}$ Kochsalz-BlutzellenSuspension, ein wenig Saponin und $0,4 \mathrm{ccm}$ destilliertes Wasser; in das andere (rechtsseitige) Gefäß gab ich $2 \mathrm{ccm}$ Blutzellen-Suspension, Saponin und $0,4 \mathrm{ccm}$ n 5 -Schwefelsäure. Nach Durchschütteln hämolysierend, lasse ich die Lösungen $5^{\prime}$ lang an der Luft stehen und verbinde sie sodann mit dem Manometerteile des Apparates. Nachdem in der Zimmertemperatur des Wasserbades das TemperaturGleichgewicht eingetreten war, ließ ich von aufwärts die vorher hereingebrachte, kalt gesättigte Ferrizyankalium-Lösung beiderseits einfließen und notierte sodann nach Aufschüttelung den Gasdruck der beiden Seiten. Der Gasdruck war auf beiden Seiten gleich; das Ferrizyankalium hatte also aus beiden Gefäßchen ein gleiches Quantum Oxygen herausgetrieben, was nur so möglich sein konnte, wenn die in das linksseitige Gefäß gegebene Säure vorher kein Oxygen austrieb.

Das gemeinsame Zusammenwirken der Säure + Ferrizyankalium erscheint durch das folgende Experiment beleuchtet:

Ich gab in das eine Gefäß (A) des Differential-Gas-AnalysierApparates $2 \mathrm{ccm}$ Kochsalz-Blutzellen und $0,2 \mathrm{ccm}$ kalt gesättigter Ferrizyankalium - Lösung, in das andere Gefäß (B) außerdem noch ein wenig Saponin; nach Aufschüttelung bleiben die Lösungen 5‘ lang an der Luft. Inzwischen muß im System B alles Oxygen entbunden sein; als Zeichen der vollzogenen Methämoglobinbildung wird die Lösung braun; im Systeme A ist keine Methämoglobinbildung eingetreten, demgemäß blieb die Suspension rot. Sodann werden die Gläschen mit dem Manometerteile verbunden; aus dem oberen Behälter lasse ich Säure in die Gefäße fließen und notiere nach vorherigem Durchschütteln den Gasdruck. $\mathrm{Da}$ in beide Gefäße die gleiche Menge Säure gelangte, ist aus beiden Gefäßen das gleiche Volum Kohlensäure vertrieben worden und kann daher die beobachtete Druckdifferenz ausschließlich vom herausgetriebenen Oxygen herstammen. Durch einen separaten Versuch bestimmte ich stets die Oxygenkapazität der Suspension, so daß ich die Menge des aus dem System A herausgetriebenen Oxygens. 
in Prozenten des gesamten (bei der Kapazitätsbestimmung erhaltenen) Oxygengehaltes ausdrücken konnte (dritte Kolumne der Tabelle VI). Nach vorgenommener Gasanalyse goß ich den Inhalt des Gefäßes A in ein Zentrifugierglas und verschaffte mir durch Zentrifugieren Ueberzeugung davon, daß Hämolyse eingetreten ist oder nicht; die Suspension war jetzt braun, und man konnte in der Suspension eine mehr oder weniger vollständige Agglutination der Blutkörperchen konstatieren. Die Ergebnisse dieser Bestimmungen sind aus Tabelle VI ersichtlich.

Tabelle VI.

\begin{tabular}{|c|c|c|c|}
\hline $\begin{array}{l}\text { Nummer } \\
\text { des } \\
\text { Versuchs }\end{array}$ & $\begin{array}{c}\text { Die Säure und } \\
\text { deren Konzentration } \\
\text { in der Suspension }\end{array}$ & $\begin{array}{c}\mathrm{O}_{2} \text { ausgetrieben } \\
\text { (in Prozenten des } \\
\text { gesamten } \mathrm{O}_{2} \text { ) }\end{array}$ & Bemerkung \\
\hline 1 & $0,015 \mathrm{n} \mathrm{H}_{2} \mathrm{SO}_{4}$ & 85 & $\begin{array}{l}\text { in Spuren hämolytisch } \\
\text { mit destilliertem Wasser }\end{array}$ \\
\hline 2 & $0,015 \mathrm{n} \mathrm{H}_{2} \mathrm{SO}_{4}$ & 72 & $\begin{array}{c}\text { vollkommen hämolysier- } \\
\text { bar }\end{array}$ \\
\hline 3 & $0,014 \mathrm{n} \mathrm{HCl}$ & 23 & $\left\{\begin{array}{c}\text { nicht hämolytisch; hämo- } \\
\text { lysierbar }\end{array}\right.$ \\
\hline 4 & $0,028 \mathrm{n} \mathrm{HCl}$ & 54 & $\left\{\begin{array}{c}\text { ein wenig hämolytisch, } \\
\text { nicht hämolysierbar }\end{array}\right.$ \\
\hline 5 & $0,084 \mathrm{n} \mathrm{HCl}$ & 92 & $\left\{\begin{array}{c}\text { nicht hämolytisch, nicht } \\
\text { hämolysierbar }\end{array}\right.$ \\
\hline
\end{tabular}

Diese Zahlen beweisen, $d a B$ bei Gegenwart eines ge wissen $Q u a n t u m s$ von Säure das Ferrizyankalium 23 bis 92 Prozent vom Hämoglobin des roten Blutkörperchens in Methämoglobin umwandelt, trotzdem die Zellen hämolysiert blieben.

In der Rubrik Bemerkung erwähne ich bei jedem Falle, ob die nach der Bestimmung zentrifugierten und ausgewaschenen roten Blutkörperchen mit destilliertem Wasser hämolysierbar waren oder nicht. Ueber die Bedeutung der Prüfung dieses Umstandes ist in meiner Abhandlung "Beobachtungen über zwei Eigentümlichkeiten der roten Blutkörperchen "Aufschluß zu finden. Einstweilen will ich bloß darauf aufmerksam gemacht haben, daß die Einwirkung des Ferrizyankaliums auch bei jenen Versuchen eine bedeutende war $(1,2,3)$, wo die Säurekonzentration nicht dazu genügte, den Zellen die Hämolysierbarkeit $z u$ nehmen. Dies beweist, daß die beiden Erscheinungen: Hämolysierbarkeit und Ferrizyansäure -Wirkung keinen engen Zusammenhang mit einander haben. Ich erwähne noch, daß das Serum, 
welches nach der Gasanalyse durch Zentrifugieren gewonnen wurde, bei Hinzugabe von Ferrichlorid eine stark blaue Farbe erhielt (Ferriferrozyanid, Berlinerblau), ein Zeichen dafür, daß während der Einwirkung ein Teil des Ferrizyankaliums reduziert worden ist. Dies entspricht jener bekannten Tatsache, daß das Ferrizyankalium, indem es das Oxy-Hämoglobin in Methämoglobin umwandelt, sich zu Ferrozyankalium reduziert.

a) Ferrizyansäure-Wirkung und Agglutination.

Es wurde oben (S. 368) bemerkt, daß nach der FerrizyansäureEinwirkung die Blutzellen meist agglutiniert gefunden worden sind. In dem Folgenden beschreibe ich eine Versuchsreihe, in der ich über das Verhältnis dieser zwei Erscheinungen Klarheit zu schaffen bestrebt war. Blutkörperchen von defibriniertem Rinderblut wurden mehrmals mit achtprozentiger Rohrzuckerlösung ausgewaschen, dann in dem 20 fachen Volum achtprozentiger Rohrzuckerlösung suspendiert. In sechs Reagenzgläser, die je $5 \mathrm{ccm}$ einer $\mathrm{m} / 8 \mathrm{~K}_{4} \mathrm{Fe} \mathrm{Cy}_{6}$ - Lösung enthielten, wurden je $1 \mathrm{ccm}$ dieser Blutkörperchen-Suspension und dann je $1 \mathrm{ccm}$ Salzsäurelösung von verschiedener Konzentration gegeben, aufgeschüttelt, von Zeit zu Zeit die sichtbaren Veränderungen verzeichnet und in einer Tabelle eingetragen. In dicear. Tabelle bedeutet + eine Agglutination, $\square$ das Braunwerden der Blutkörperchen (Methämoglobinbildung); das Minuszeichen bedeutet, daß keine Agglutination, das Kreiszeichen (o), daß keine Farbenänderung auftritt.

Tabelle VII.

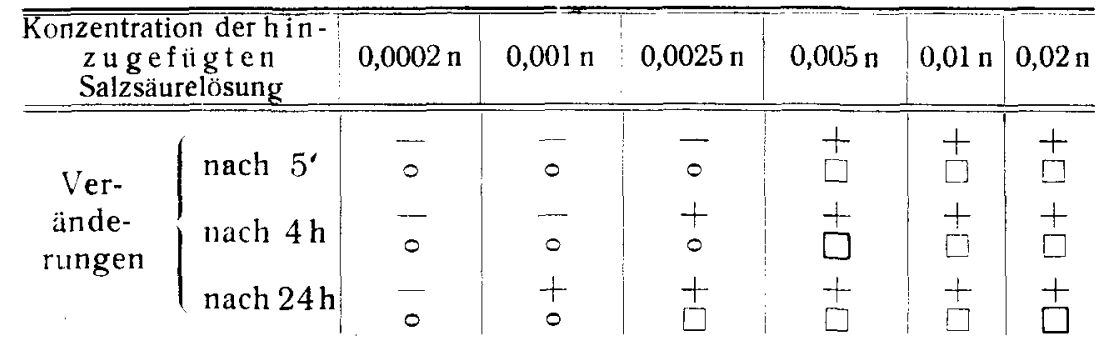

Es ist ersichtlich, daß 1. zur Methämoglobinbildung in diesen Versuchen viel kleinere Säurekonzentrationen genügten, wie in den Versuchen mit Kochsalz - Blutzellen -Suspensionen (Tabelle VI); 2. daß Agglutination und Methämoglobinbildung nicht immer zusammenfallen, vielmehr daß die Agglutination der Methämoglobinbildung immer 
vorausgeht. Auf die Bedeutung dieser Tatsache werden wir in dem nächsten Kapitel zurückkommen.

IV.

\section{Diskussion.}

Meine Untersuchungen bestätigen vor allem, daß die Elektrolytaufnahme der roten Blutkörperchen Io ne $\mathrm{n}$ a u $\mathrm{n}$ ahme darstellt. Den physikochemischen Verlauf dieser Ionenaufnahme betreffend, führen meine Untersuchungen zur Erkenntnis dessen, daß dieser Vorgang keine Membran-Diffusion sein kann. Wir haben gesehen, daß die Nitrit- und Chlorateinwirkung und deren mannigfache Beeinflussungen in der Zelle und in einer Hämoglobinlösung fast ganz in derselben Weise von statten gehen. In meiner Abhandlung: „Beobachtungen über zwei Eigentümlichkeiten der roten Blutkörperchen " und in meiner mit $\mathrm{A}$. L óránt gemeinsam ausgeführten Abhandlung: „Zur Kenntnis der Wirkung von $\mathrm{CO}_{2}$ und $\mathrm{O}_{2}$ auf die Elektrolytpermeabilität der roten Blutkörperchen " sind dann noch mehrere Erscheinungen in den Blutkörperchen und in einer Hämoglobinlösung verglichen, wobei sich eine fast durchgehende Identität der Reaktionsumstände herausgestellt hat. Die sehr kleinen Unterschiede im Verhalten von Blutkörperchen einerseits und hämolysiertem Blute andererseits in bezug auf diese Erscheinungen sind offenbar dadurch bedingt, dab das Blutkörperchen auch „ohne Membran" hinsichtlich der Konzentration des Hämoglobins und der Elektrolyte usw. von dem hämolysierten Blute jedenfalls differiert. Es ist bei Vorhandensein einer Lipoid- (oder im allgemeinen einer nicht aus Hämoglobin bestehenden) Membran undenkbar, wie die mannigfachsten Stoffe auf das gelöste Hämoglobin dieselbe Wirkung ausüben können bezw. die Wirkung eines Stoffes auf dieselbe Weise beeinflussen können, als die auf das Zellen-Hämoglobin; würde doch die Membran einigen Stoffen den Eintritt gewähren, anderen Stoffen verwehren usw. Vermissen wir also in allen diesen Erscheinungen jede Spur einer solchen Membranwirkung, so bedeutet das, dab eine solche Membran eben nichtexistiert und dab die Blutkörperchen-Oberfläche im wesentlichen eine Hämoglobin-Oberflächedarstellt.

Zur Beantwortung der Frage nach den physiko-chemischen Vorgängen bei der lonenaufnahme in die Blutkörperchen dienten mir jene bekannten kolloidchemischen Prinzipien als Ausgangspunkt, welche sich auf die Elektrolytaufnahme suspensoider Kol- 
loide, oder grob suspendierter Teilchen, beziehen. Wir wissen, daß die Elektrolytaufnahme der Suspensoide durch Adsorption geschieht, und die Art, sowie die Menge des aufgenommenen Ions, in erster Reihe davon bedingt ist, welcher Art $(+$ oder -$)$ und wie stark die elektrische Ladung des suspendierten Teilchens ist. Hinsichtlich des Mech a n is mus der Aufnahme wurde folgende Theorie allgemein akzeptiert (Fre undlich): Die Ladung irgend eines suspendierten Kolloides wird durch die (während ihrer Herstellung adsorbierten) Elektrolyte erzeugt; das Kolloid bindet beide Ionen des Elektrolyten, von diesen aber adsorbiert es, seiner chemischen Natur entsprechend, bloß das Anion oder bloß das Kation, das andere Ion wird durch seine elektrostatische Anziehung auf der Oberfläche des Teilchens festgehalten. Das Kolloid Ferrihydroxyd hält z. B. Ferrichlorid in Spuren adsorbiert; das Fet++-Ion verleiht dem Kolloid die Ladung (auf der inneren Seite der Doppel-Schicht), das Chlor-Ion dagegen bleibt, seiner elektrostatischen Ladung zufolge, auf der äußeren Seite der Doppel-Schicht. Gibt man das Kolloid in die Lösung irgend eines (anderen) Salzes, so werden sich die Anionen, ihrem osmotischen Drucke zufolge, austauschen; die fester gebundenen Kationen dagegen werden nicht ausgetauscht. Dieser Mechanismus der Aufnahme gibt in der Kolloidchemie unter anderem Aufklärung darüber, weshalb bei der Ausflockung positiv geladener Kolloide die Anionen, und bei der Ausflockung negativer Kolloide die Kationen mabgebend sind.

Die Tatsache des lonenaustausches in diesen Erscheinungen erscheint übrigens durch quantitative Messungen bestätigt. Es wurde ituch festgestellt, daB die Aufnahme irgend eines Anions durch andere Anionen gehemmt werden kann; daß die Zahl der aufgenommenen Anionen durch Hinzugabe von Säure bedeutend erhöht und durch Lauge gehemmt wird, daß ferner der elektrochemische Wert des lons eine große Rolle spielt usw.

Die Elektrolytaufnahme der roten Blutkörperchen betrachte ich nun für eine Erscheinung, welche im wesentlichen mit der Elekrolytaufnahme suspensoider Kolloide identisch ist. Durch Anwendung dieser These können die gesamten Erscheinungen der "Anionenpermeabilität “ der roten Blutkörperchen unschwer erklärt werden.

Die Hämoglobinoberfläche der roten Blutkörperchen enthält Chlorlonen (und Phosphat-, Karbonat- und andere Anionen) adsorbiert. Diese lonen können sich mit anderen Anionen vertauschen und sind durch Waschen mit der Lösung eines solchen Anions $\left(\mathrm{Br}{ }^{\prime}, \mathrm{NO}_{z}{ }^{\prime}, \mathrm{ClO}_{3}\right)$ aus der Zelle vollständig zu entfernen. Die im Serum oder in neutraler Lösung megativ geladene Zellenoberfläche nimmt Anionen $\left(\mathrm{NO}_{2}, \mathrm{ClO}_{3}\right.$ usw.) 
in Anwesenheit von Säure in weit größerer Zahl auf, denn das $\mathrm{H}^{+}$Ion der Säure - auf die Hämoglobin-Oberfläche adsorbiert - verleiht ihr positive Ladung; die Anionen der Säure können dann durch die vorhandenen anderen Anionen $\left(\mathrm{NO}_{2}{ }^{-}, \mathrm{ClO}_{3}{ }^{--}\right.$usw.) verdrängt und letztere auf diese Weise aufgenommen werden. Durch diese einfachen Annahmen. können sämtliche Erscheinungen, die ich in der Zusammenfassung (s. weiter unten) in den $1-5$ Punkten aufzähle, ungezwungen erklärt werden.

Die übrigen Erscheinungen betreffend, müssen wir vor Augren halten, daß das gelöste Hämoglobin bei einer $\mathrm{H}^{+}$-Konzentration $1,8 \cdot 10^{-7}$ (also in ungefähr neutraler Lösung) keine bestimmte elektrische Ladung besitzt; demgegenüber wandern die roten Blutkörperchen: in neutraler Lösung anodisch, besitzen also negative Ladung. Diesen Tatsachen entsprechend, kann das gelöste Hämoglobin, wie wir gesehen haben, in neutraler Lösung größere Mengen Nitrit und Chlorat aufnehmen, als die dieselben Mengen Hämoglobin enthaltenden roten Blutkörperchen.

Das Wesen der Ferrizyanwirkung erheischt, eingehender erörtert zu werden, da diese, wie ich schon bemerkt habe, bisher als eine wichtige Stütze der „Membran-Theorie“ galt. Die Ferrizyanwirkung verläuft nämlich in einer Hämoglobinlösung scheinbar gänzlich anders, als in einer Blutkörperchen-Suspension. Das Wesen dieser Verschiedenheit besteht nach meinen Versuchen darin, daß das Ferrizyankalium auf das gelöste Hämoglobin auch in neutraler Lösung einzuwirken vermag, während es zur Einwirkung auf das Hämoglobin des unversehrten roten Blutkörperchens einer (unter Umständen beträchtlichen) Säurekonzentration bedarf. Die Untersuchung des Zusammenhanges zwischen der Methämoglobin bildenden und agglutinierenden Wirkung der Ferrizyansäure führte zur richtigen Deutung dieser Verschiedenheit in dem Verhalten binnen und außer dem Blutkörperchen. Wir haben gesehen, daß die methämoglobinbildende Wirkung des Ferrizyansäuregemisches in der Blutzelle immer von einer Agglutination begleitet wird, und zwar entsteht bei steigenden Säuremengen i m mer erst Agglutination und dann Methämoglobinbildung. Nun wissen wir, daB die Säureagglutination eine elektrochemische Erscheinung ist ${ }^{1}$ ): die natürliche negative Ladung der Blutkörperchen wird durch die $\mathbf{H}^{+}$-Ionen der Säure neutralisiert, worauf eine Ausflockung einiritt.

1) Höber, Pflüger's Arch. 101, 607 (1904); Bech hold, Zeitschr. f. physì̀. Chem. 48, 385 (1904). 
Durch das Ferrizyansäuregemisch werden also die Blutkörperchen erst entladen (Agglutination), dann positiv aufgeladen, und erst dann wird das Ferrizyan-Ion aufgenommen (Methämoglobinbildung). Hingegen kann sich das adsorbierte Chlor-Ion des gelös te n Hämoglobins schon in neutraler Lösung mit Ferrizyan-Ion vertauschen, da das gelöste Hämoglobin, wie erwähnt, in neutraler Lösung keine bestimmte elektrische Ladung besitzt.

Die Tatsache, daB - wie wir gesehen haben - die Nitrit- und Chlorataufnahme durch einwertige Anionen gehemmt wird, findet seine einfache Lösung darin, daß durch letztere jene von der Oberfläche der Hämoglobinteilchen verdrängt werden. Die gefundene Unwirksamkeit der Kationen, die wirkenden Hydrogen- und Schwermetallkationen ausgenommen, ferner die Unwirksamkeit a lle r Nichtelektrolyte, erscheint hiernach als selbstverständlich. Dagegen muß nach unserer Theorie die Aufnahme der Anionen $\mathrm{NO}_{2}^{--}$und $\mathrm{ClO}_{3}{ }^{-}$durch Hydrogen- und Schwermetallkationen, ferner durch Kolloide positiver Ladung, durch welche die negative Ladung der Zellenoberfläche aufgehoben wird, beschleunigt werden; dies wurde in meinen Versuchen bestätigt. Daß eine solche Auffassung dieser letzteren Tatsachen richtig ist, wird dadurch bewiesen, daß - wie wir gesehen haben - alle die $\mathrm{NO}_{2}$ und $\mathrm{ClO}_{3}$ (und Ferrizyan-)-Aufnahme befördernden Stoffe zugleich a g g l u tinierend, also die negative Ladung der Blutkörperchen aufhebend wirken.

Wir haben gesehen (s. S. 369), daß die methämoglobinbildende Wirkung des Ferrizyankaliums auf Rohrzuckerblutkörperchen bei viel kleineren Säurekonzentrationen erfolgt, als es bei der Wirkung auf Kochsalzblutkörperchen der Fall ist. Wir erinnern daran, daß auch zur Säureagglutination der Blutkörperchen viel kleinere Säurekonzentrationen genügen, wenn die Blutkörperchen in einer Rohrzuckerlösung, als wenn sie in einer (physiol.) Kochsalzlösung suspendiert sind (S. 369).

Die Aufnahme der Nitrit- und Chlorat-lonen wird - wie wir gesehen haben - von Anionen zwei- und dreifacher Ladung viel weniger gehemmt, als von einwertigen Anionen. Wir fassen das als eine Folge der Tatsache auf, daß zwei- und dreiwertige Anionen auf negative Oberflächen in viel geringerem Maße adsorbieit werden; demgemäß können durch diese Ionen das $\mathrm{NO}_{2}^{-}$und $\mathrm{ClO}_{3}$ - Ion von der Oberfläche nicht verdrängt werden. Dieser Auffassung gemäß, kann die Untersuchung der Nitrit- oder Chlorateinwirkung hinsichtlich der Auf $n$ ahme e in es beliebigen Ions Aufschluß geben. Es muß nämlich die methämo- 
globinbildende Wirkung der $\mathrm{NO}_{2}$ und $\mathrm{ClO}_{3}$-Ionen auf rote Blutkörperchen durch andere aufnahmsfähige (= permeable) Anionen gehemmt, durch aufnahmsfähige Kationen beschleunigt werden; impermeable Ionen werden aber die Reaktion nicht beeinflussen können. Wir haben z. B. gesehen, dab $\mathrm{KClO}_{3}$ die Nitritwirkung nur in sehr großen Konzentrationen zu hemmen vermag (Tabelle V, C, S. 355). Daraus folgt, dab dieses Anion überhaupt nicht, oder nur in minimalen Mengen in das rote Blutkörperchen aufgenommen wird. Daf diese Folgerung richtig ist, wurde durch meine Versuche mit $\mathrm{K} \mathrm{ClO}_{3}$ (S. 352) in ganz eklatanter Weise bewiesen; es hat sich herausgestellt, daß dieses Ion nur bei höheren Temperaturen $\left(38^{\circ} \mathrm{C}\right)$ aufgenommen wird.

Ich habe schon bei einer früheren Gelegenheit auf Grund meiner älteren Versuche über die elektromotorische Kraft der Niederschlagsmembranen ${ }^{1}$ ) und über die Theorie der bioelektrischen Ströme ${ }^{2}$ ) auf die Notwendigkeit einer genauen Definition der "Ionenpermeabilität" hingewiesen. Ich bin in jenen Untersuchungen zu dem Resultat gelangt, daß die Erscheinungen der Ionenpermeabilität der Zelle nicht durch den Unterschied der Wanderungsgeschwindigkeit der Kationen und Anionen in der Zellmembran bedingt werden. Ich habe dort darauf hingewiesen, daB die quantitativ verschiedene Kationen- und Anionenadsorption an der Zelloberfläche notwendigerweise die chemischen und elektrochemischen Erscheinungen der lonenpermeabilität erzeugt (loc. cit. S. 236). Ich glaube, dab es mir gelungen ist, in vorliegender Arbeit letztere Hypothese zu stützen.

Ich erwähnte bereits und betone hier nochmals, daß das Hauptgewicht bei dieser neuen Theorie der Elektrolytpermeabilität der Blutkörperchen nicht auf die Ionenadsorption, sondern darauf zu legen ist, daß die Elektrolytaufnahme der Zelle mit jenem Phänomen identisch ist, welches die Elektrolytaufnahme von fein suspendierten strukturlosen Teilchen (Mastix-, Kohlesuspension) oder von Suspensionskolloiden begründet. In der Kolloidchemie wird heute in der Theorie dieser Erscheinungen allgemein von dem Begriff der Io nenadsorption ausgegangen, und mit Hilfe desselben ist es tatsächlich möglich, diese Erscheinungen - und, wie dies ausgeführt wurde, auch die Elektrolytaufnahme der roten Blutkörperchen - befriedigend auszulegen. Mancherseits wird demgegenüber die Hypothese aufgestellt, daB das Ion

1) H. Rohonyi, Ionenpermeabilität und Membranpotential. (Bioclıem. Zeitschr. 66, 231, 1914.)

2) H. Rohonyi, Zur Theoric der bioelektrischen Ströme. (Biochem. Zeitschr. 66, 248, 1914.) 
auf der Oberfläche von kolloiden Teilchen $\mathrm{chem}$ is $\mathrm{ch}$ gebunden wird; dieser Ausgangspunkt besitzt den Vorteil, daß durch denselben die etwaigen spez if i schen Einwirkungen der lonen leichter verständlich gemacht werden können. Im Laufe meiner Experimente wurden zwei Tatsachen erkannt, welche darauf hinzuweisen scheinen, daß die Ionenaufnahme der roten Blutkörperchen nicht durch Adsorption, sondern durch chemische Bindung erfolgt. Die eine Tatsache ist, daB $\mathrm{K} \mathrm{ClO}_{3}$ in die roten Rinderblutzellen bei Zimmertemperatur nicht aufgenommen wird, sondern erst bei $37^{\circ} \mathrm{C}$; die andere Tatsache ist aber, daß bloß größere Salzkonzentrationen die Nitritreaktion der suspendierten roten Blutzellen hemmen, Spuren von Elektrolyten dagegen dieselbe beschleunigen. Die erste Tatsache bedeutet, daB die Chlorataufnahme ein solcher Prozeb ist, welcher erst bei erhöhter Temperatur erfolgt, bezw. durch Erhöhung der Temperatur in sehr großem Maße beschleunigt wird; dies ist bekanntlich nicht die Eigenschaft einer Adsorption, kann aber die Eigenschaft einer chemischen Reaktion sein. Die zweite Tatsache besagt hinwieder, daß ein Anion die Aufnahme eines anderen Anions beschleunigen kann; dies wäre schwer verständlich, wenn die Aufnahme des Ions durch Adsorption erfolgen würde, ist aber möglich, wenn eine chemische Reaktion vorausgesetzt wird. Hierfür spricht vielleicht auch der Um. stand, daß die Anionenreihen sich unabhängig von der $\mathrm{H}^{+}$-Konzentration des Mediums gestalten (S. 360), pflegt doch bei lediglich auf elektrische Ladung ankommenden Erscheinungen den beiden Seiten des isoelektrischen Punktes eine lonenreihenfolge entgegengesetzter Richtung zu entsprechen.

\section{Zusammenfassung.}

1. Die roten Blutkörperchen von Rinderblut vermögen beträchtliche Nitritmengen aufzunehmen; ihr gesamter Oxyhämoglobingehalt kann dadurch in Methämoglobin umgewandelt werden.

2. Aus der Lösung von $\mathrm{Ca}\left(\mathrm{NO}_{2}\right)_{2}$ wird nur der Nitritbestandteil aufgenommen; das Kalzium bleibt in der Lösung.

3. Durch Waschen mit $\mathrm{NaNO}_{2}$ kann fast der ganze Chlorgehalt von Rinderblutkörperchen entfernt werden; durch erneutes Waschen mit physiol. Kochsalzlösung treten dann wiederum Chlor-Ionen ein.

4. Durch das Nitrit-Ion kann das Chlor-Ion auch gegen ein osmotisches Druckgefälle aus dem roten Blutkörperchen getrieben werden.

5. Die Nitritaufnahme kann nur durch elektrisch geladene Teilchen beeinfluft werden, und zwar beschleunigen im allgemeinen die positiv geladenen Teilchen, während negative Teilchen hemmend wirken. 
6. Die Anionenreihe der hemmenden Wirkung ist: Rhodanid $>$ Oxalat $>$ Nitrat $>$ Jodid, Chlorid $>$ Sulfat. Diese Anionenreihe kann durch Aenderung des Hydrogeniongehaltes des Mediums nicht geändert werden. In sehr verdünnten Lösungen wirken dieselben Anionen beschleunigend auf die Nitritaufnahme.

7. Alle diese Beeinflussungen auf das hämolysierte Blut und auf die Lösung von kristallisiertem Hämoglobin gestalten sich in fast identischer Weise und zwar nicht nur im Falle der Nitritwirkung, sondern auch im Falle der Chloratwirkung. Das Chlorat-Ion wird nur bei höherer Temperatur $\left(38^{\circ} \mathrm{C}\right)$ aufgenommen.

8. Das Ferrizyan-lon wirkt in neutraler Lösung nur auf hämolysiertes Blut, nicht aber auf die Blutkörperchen. Von einer bestimmten Säurekonzentration an wirkt es aber momentan auch auf die Blutkörperchen.

9. In Gegenwart von Ferrizyankalium und gewisser Mengen Säure kommt in einer Suspension von mit Rohrzuckerlösung ausgewaschenen roten Blutkörperchen immer auch eine Agglutination zustande. Die Agglutination geht ein wenig der Methämoglobinbildung voraus.

10. Die Blutkörperchen besitzen keine spezielle Membran; die Blutkörperchenoberfläche besteht - wie das Innere - hauptsächlich aus Hämoglobin.

11. Die Ionenaufnahme der roten Blutkörperchen beruht auf demselben physikalisch-chemischen Vorgang, wie die Elektrolytaufnahme von grob suspendierten Teilchen und von Suspensionskolloiden. 